\title{
Modeling Gunshot Bruises in Soft Body Armor with an Adaptive Fuzzy System
}

\author{
Ian Lee, Bart Kosko, Member, IEEE, and W. French Anderson
}

\begin{abstract}
Gunshots produce bruise patterns on persons who wear soft body armor when shot even though the armor stops the bullets. An adaptive fuzzy system modeled these bruise patterns based on the depth and width of the deformed armor given a projectile's mass and momentum. The fuzzy system used rules with sinc-shaped if-part fuzzy sets and was robust against random rule pruning: Median and mean test errors remained low even after removing up to one fifth of the rules. Handguns shot different caliber bullets at armor that had a $10 \%$-ordnance gelatin backing. The gelatin blocks were tissue simulants. The gunshot data tuned the additive fuzzy function approximator. The fuzzy system's conditional variance $V[Y \mid X=x]$ described the second-order uncertainty of the function approximation. Handguns with different barrel lengths shot bullets over a fixed distance at armor-clad gelatin blocks that we made with Type 250 A Ordnance Gelatin. The bullet-armor experiments found that a bullet's weight and momentum correlated with the depth of its impact on armor-clad gelatin $\left(R^{2}=0.881\right.$ and $p$-value $<0.001$ for the null hypothesis that the regression line had zero slope). Related experiments on plumber's putty showed that highspeed baseball impacts compared well to bullet-armor impacts for large-caliber handguns. A baseball's momentum correlated with its impact depth in putty $\left(R^{2}=0.93\right.$ and $p$-value $\left.<0.001\right)$. A bullet's momentum similarly correlated with its armor-impact in putty $\left(R^{2}=0.97\right.$ and $p$-value $<0.001)$. A Gujarati-Chow test showed that the two putty-impact regression lines had statistically indistinguishable slopes for $p$-value $=0.396$. Baseball impact depths were comparable to bullet-armor impact depths: Getting shot with a .22 caliber bullet when wearing soft body armor resembles getting hit in the chest with a 40-mph baseball. Getting shot with a .45 caliber bullet resembles getting hit with a 90-mph baseball.
\end{abstract}

Index Terms-Adaptive fuzzy systems, body armor, bruise modeling, bullet backface signature, function approximation, tissue simulant.

\section{MODELING BulLET-ARMOR BRUISE IMPACTS}

H OW does it feel to get shot while wearing soft body armor? One police officer described it as a sting while another officer described it as a "hard blow" [1]. Fig. 1 shows the bruise beneath the armor after a .44 caliber bullet struck a police officer's upper left chest. The armor stopped the bullet but the impact still injured soft tissue.

Manuscript received June 2, 2004. This paper was recommended by Associate Editor C. M. Helgason.

This paper has supplementary downloadable material available at http://ieeexplore.ieee.org35tsmcb06-lee-mm.zip, provided by the authors. This includes 12 color figures. This material is $9.6 \mathrm{MB}$ in size.

I. Lee and B. Kosko are with the Department of Electrical Engineering, University of Southern California, Los Angeles, CA 90089-2564 USA (e-mail: kosko@usc.edu).

W. F. Anderson is with the Gene Therapy Laboratories, Keck School of Medicine, University of Southern California, Los Angeles, CA 90089-9176 USA

Digital Object Identifier 10.1109/TSMCB.2005.855585

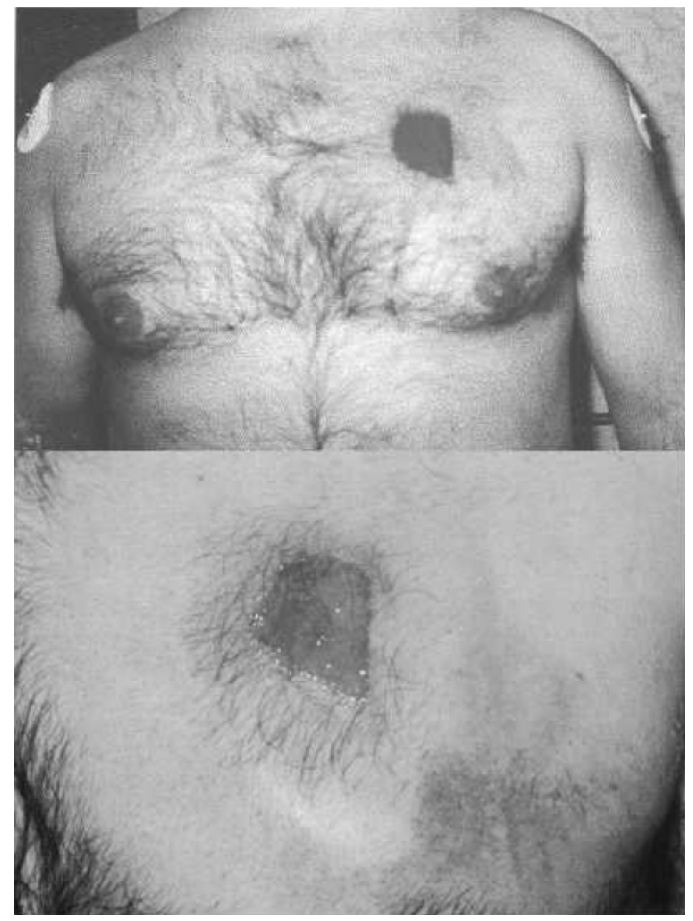

Fig. 1. (Top) Actual bruise from a police officer shot by a .44 caliber weapon in the line of duty while wearing soft body armor. (Bottom) Close-up of the "backface signature" bruise in the top photo. Note that the bruise includes the discoloration around the wound. Photo reproduced with permission from the IACP/Du Pont Kevlar Survivors' Club.

We examined the bruising effect with a fuzzy function approximator and a baseball analogy. Bullet-impact experiments produced the bullet-armor bruise data that generated a quantitative bruise profile and a baseball-impact comparison. The bruise profile gave the depth and width of the deformation that a handgun bullet made on gelatin-backed armor for gelatin blocks that we made with Type 250 A Ordnance Gelatin (from Kind \& Knox Gelatin).

Few researchers have studied the relationship between the bruising effect and the so-called backface signature or the deformation in the armor's backing material after a gunshot [2], [3]. Our bruise profile modeled the bullet-armor bruise with the depth and width of the deformation as a blunt object that could injure soft tissue. We quantified the bullet-armor impacts and baseball impacts on a common backing material—plumber's putty. The baseball analogy helped estimate gunshot impacts on armor. We found that a fast baseball could hit as hard as a large-caliber handgun bullet on armor. The baseball and bullet impacts in putty had similar depths and statistically indistinguishable regression slopes. 
TABLE I

SUMMARY OF LineAR REgRESSION STATISTICS FOR THE GELATIN-BACKED BULLET-ARMOR IMPACT EXPERIMENTS AND FOR THE SIMPLE LINEAR MODEL $y=\beta_{0}+\beta_{1} x$

\begin{tabular}{|c|c|c|c|c|}
\hline $\begin{array}{r}\text { DEPTH } \\
\text { REGRESSION }\end{array}$ & $R^{2}$ & $\beta_{0}$ & $\beta_{1}$ & $\begin{array}{c}\mathbf{H}_{0}: \beta_{1}=0 \\
t(p \text {-value })\end{array}$ \\
\hline WEIGHT & 0.880 & 5.385 & 0.280 & $19.892(p<0.001)$ \\
\hline MOMENTUM & 0.741 & 9.443 & 13.718 & $12.415(p<0.001)$ \\
\hline KINETIC ENERGY & 0.474 & 20.225 & 0.066 & $6.972(p<0.001)$ \\
\hline SPEED & 0.089 & 79.885 & -0.124 & $-2.298(p=0.025)$ \\
\hline TARGET DISTANCE & 0.415 & 29.328 & -1.203 & $-4.453(p<0.001)$ \\
\hline $\begin{array}{r}\text { WIDTH } \\
\text { REGRESSION }\end{array}$ & $R^{2}$ & $\beta_{0}$ & $\beta_{1}$ & $\begin{array}{c}\mathbf{H}_{0}: \beta_{1}=0 \\
t(p \text {-value })\end{array}$ \\
\hline WEIGHT & 0.865 & 84.816 & 0.421 & $18.580(p<0.001)$ \\
\hline MOMENTUM & 0.745 & 90.295 & 20.870 & $12.566(p<0.001)$ \\
\hline KINETIC ENERGY & 0.482 & 106.478 & 0.101 & $7.094(p<0.001)$ \\
\hline SPEED & 0.079 & 194.170 & -0.177 & $-2.153(p=0.036)$ \\
\hline TARGET DISTANCE & 0.004 & 58.162 & 0.1082 & $0.340(p<0.001)$ \\
\hline
\end{tabular}

See the text below for more details.

An adaptive fuzzy system learned to model the depth and width of bruise profiles from the bullet-armor impact experiments. Two armor-impact experimental setups used gelatin blocks to simulate human tissue. A third armor-impact experimental setup used plumber's putty to record the bullet-armor deformation that compared with baseball impacts. The experiments confirmed the expectation that a bullet made a larger impact if it had a larger caliber or a larger momentum (see Table I). But a larger and slower handgun bullet hit harder than a smaller and faster one in the experiments. Impact depth correlated better with momentum than with kinetic energy. This corroborated the finding that kinetic energy was not a good predictor of bullet penetration wounds [4].

Table I presents the key correlations that we found in the experiments. Momentum $m v$ and weight $m$ correlated with an impact's depth and width while kinetic energy $(1 / 2) m v^{2}$ correlated the least. Target distance $d$ correlated with an impact's depth while speed $v$ and distance $d$ correlated little with the impact's width. The $R^{2}$ measures the strength of the correlation between the input and output variables. The $t$ statistic tested the parameter significance of a single regression coefficient $\beta_{1}$ between deformation in millimeters and one of a bullet's mean weight (grain), momentum $(\mathrm{kg} \mathrm{m} / \mathrm{s})$, kinetic energy $\left(\mathrm{kg} \mathrm{m}^{2} / \mathrm{s}^{2}\right)$, target distance (yard), and speed $(\mathrm{m} / \mathrm{s})$. The $p$-value measured the credibility of the null hypothesis $\mathbf{H}_{0}$ that the regression line had zero slope $\beta_{1}=0$ or that a dependent variable did not vary with the independent variable. A statistical test rejects the null hypothesis $\mathbf{H}_{0}$ at a significance level $\alpha$ if the $p$-value is less than that significance level. So the regression rejects the null hypothesis $\mathbf{H}_{0}$ for the customary significance levels $\alpha=0.05$ and $\alpha=0.01$ because $p$-value $<0.001$.

We picked the initial rules based on our ballistic judgment and experience. The experimental data tuned the rules of an adaptive standard-additive-model (SAM) fuzzy system [5]. The SAM system used two scalar subsystems to model the depth and width of a bullet-armor impact in parallel given the bullet's weight and momentum. We tested the robustness of the fuzzy system by removing rules in a random rule pruning. The median, mean, and maximal test errors resembled the initial approximation error for pruning that randomly removed up to $20 \%$ of the rules.

The next two subsections review soft body armor and bulletimpact bruises. Section II reviews rule-based fuzzy function approximation. Section III reviews the standard additive model. Section IV provides the setup and results of the bullet-armor experiments. Section $\mathrm{V}$ provides the setup and results of the baseball impact experiments. Section VI provides the experimental setup and the results of the fuzzy function approximation.

\section{A. Soft Body Armor}

Soft body armor prevents most handgun bullets from penetrating a user's body [6]. Our armor experiments used a generic armor that we made by combining many layers of fabric that wove together Kevlar fibers. Thinner armor is softer than thicker armor. Another type of armor material laminated together many layers of parallel fibers. Both types of armor deform under a bullet's impact and spread the impact's force over a wider area. Bullets penetrate by crushing [7]. So soft body armor arrests a handgun bullet by reducing its crushing force below a material-failure threshold [7].

Failure analysis does not consider the physiological effects as the armor stops a bullet. Some researchers define armor failure as material failure such as broken fibers or breached fabric layers [8]-[12]. Others require complete bullet passages [13]. Such definitions do not address the interactions that flexible armor permits with the underlying material.

These interactions have two effects. The first is that a bulletarmor impact can injure soft tissue even though the bullet does not penetrate the armor (see Fig. 1). The second effect is that soft body armor's performance can differ for different backing material that supports the armor [7]. We found that a hammer strike breached several layers of concrete-backed armor fabric. But 


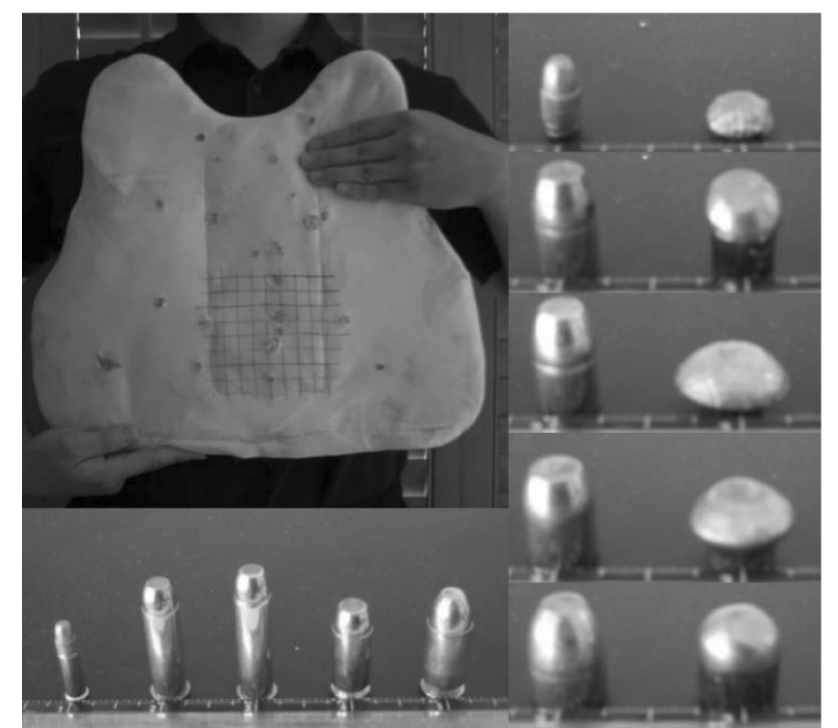

Fig. 2. One of the authors holds a 14-ply Kevlar soft body armor panel (from a Superfeatherlite vest from Second Chance) and some sample cartridges (.22, $.38, .357$ magnum, .40 , and .45 caliber). The right side of the image shows the pristine and armor-deformed bullets for the five calibers.

at least one handgun bullet bounced off gelatin-backed armor fabric.

The backface signature is the deformation in the backing material after a bullet strikes armor [3]. Studies of backface signatures [2] give little information about the impact as a bruising force if the backing material differs from soft tissue. One industry standard [3] measures the backface signature on a clay backing material. The clay records the impact in a plastic or permanent backface deformation but its properties differ from soft tissue.

Gelatin tissue simulant is elastic and responds to a bullet's crushing force similar to how soft tissue responds in bulletpenetration tests [14]-[16]. So testing gelatin-backed soft body armor can help study the performance of the armor on a user's body. We performed the bullet-armor impact experiments on tissue simulant and defined a simple two-parameter bruise profile to describe the impact.

\section{B. Bruising and the Bruise Profile}

Bruising implies injury but need not indicate the severity of the injury. A bruise is escaped blood in the intercellular space after a blunt impact injures soft tissue [17]. The visible part of a bruise is the part of the escaped blood that is close to the skin surface. Scraping with a coin or a spoon can leave extensive but superficial bruises or welts that resemble bruises from abuse [18]. The visible bruise can change over time [19] at different rates based on sex, age, body fat [17], and medication [20]. So a bruise shows that a blunt impact occurred but need not show that internal injuries occurred [21], [22]. This can occur in sports injuries where soft tissue injuries can escape detection [23].

A bruise profile models the shape of the bullet-armor impact and can help guide the examination after an armor gunshot. This is similar to a wound profile that can help the examination of a gunshot wound [16]. The bruise profile can indicate the affected internal tissue beneath the visible armor bruise.
TABLE II

INITIAL FUZZY RULES FOR THE FUNCTION APPROXIMATION

\begin{tabular}{|c|c|c|c|c|c|c|c|c|}
\hline \multirow{2}{*}{$\begin{array}{l}\text { (a) DEPTH } \\
\text { RULES }\end{array}$} & \multicolumn{8}{|c|}{$X_{2}$ : MOMENTUM } \\
\hline & & vs & SM & MS & MD & ML & LG & $\mathrm{VL}$ \\
\hline \multirow{7}{*}{$\begin{array}{c}X_{1} \\
\text { WEIGHT }\end{array}$} & VL & MD & MD & MD & \multirow{7}{*}{$\begin{array}{l}\text { LG } \\
\text { LG } \\
\text { MD } \\
\text { MD } \\
\text { SM } \\
\text { SM } \\
\text { SM }\end{array}$} & LG & LG & $\mathrm{VL}$ \\
\hline & LG & MD & MD & MD & & LG & LG & $\mathrm{VL}$ \\
\hline & ML & MD & MD & MD & & MD & MD & LG \\
\hline & MD & SM & MD & MD & & MD & MD & LG \\
\hline & MS & SM & SM & SM & & SM & MD & LG \\
\hline & SM & SM & SM & SM & & SM & $\mathrm{MD}$ & MD \\
\hline & vs & vs & vs & vs & & SM & MD & MD \\
\hline \multirow{2}{*}{$\begin{array}{l}\text { (b) WIDTH } \\
\text { RULES }\end{array}$} & \multicolumn{8}{|c|}{$X_{2}$ : MOMENTUM } \\
\hline & & vs & SM & MS & MD & ML & LG & VL \\
\hline \multirow{7}{*}{$\begin{array}{c}X_{1} \\
\text { WEIGHT }\end{array}$} & VL & MD & MD & MD & \multirow{7}{*}{$\begin{array}{l}\text { MD } \\
\text { SM } \\
\text { SM } \\
\text { SM } \\
\text { vS } \\
\text { vS } \\
\text { vS }\end{array}$} & LG & LG & $\mathrm{VL}$ \\
\hline & LG & SM & SM & MD & & LG & LG & $\mathrm{VL}$ \\
\hline & ML & SM & SM & SM & & MD & LG & VL \\
\hline & MD & SM & SM & SM & & MD & MD & LG \\
\hline & MS & vs & vs & vs & & SM & MD & LG \\
\hline & SM & vS & vS & vS & & SM & MD & MD \\
\hline & vs & vs & vs & vS & & SM & MD & MD \\
\hline \multirow{2}{*}{$\begin{array}{l}\text { (c) THEN-PART } \\
\text { DISPERSION }\end{array}$} & \multicolumn{8}{|c|}{$X_{2}$ : MOMENTUM } \\
\hline & & vS & SM & MS & MD & ML & LG & VL \\
\hline \multirow{7}{*}{$\begin{array}{c}X_{1} \\
\text { WEIGHT }\end{array}$} & $\mathbf{V L}$ & LG & LG & MD & \multirow{7}{*}{$\begin{array}{l}\text { MD } \\
\text { MD } \\
\text { MD } \\
\text { SM } \\
\text { SM } \\
\text { MD } \\
\text { MD }\end{array}$} & LG & MD & SM \\
\hline & LG & LG & LG & MD & & MD & SM & SM \\
\hline & ML & LG & MD & MD & & MD & SM & SM \\
\hline & MD & MD & MD & MD & & SM & SM & SM \\
\hline & MS & MD & MD & MD & & SM & SM & MD \\
\hline & SM & SM & SM & MD & & MD & LG & LG \\
\hline & vs & SM & SM & MD & & MD & LG & LG \\
\hline
\end{tabular}

See the text below for more details.

\section{ADAPTIVE FUZZY SYSTEM}

Bullet-impact experiments trained an adaptive fuzzy system to model the depth and width of the bullet-armor impact given a handgun bullet's weight and momentum. We picked the fuzzy system's initial rules in Table II based on the correlations in the experimental data (see Table I) and based on our ballistic judgment and experience. Similar rules described the depth and width subsystems.

Each entry in Table II represented one rule for the depth subsystem in (a) and width subsystem in (b). We based the 49 initial fuzzy rules for the armor-deformation depth and width on the experimenters' ballistic judgment and experience. Each rule had a two-dimensional if-part set function $a_{j}$ and two parallel scalar then-part set functions $b_{j}$. The functions $a_{j}$ had parameters $\left(X_{1}, X_{2}\right)$ based on a bullet's weight and momentum. The functions $b_{j}$ had center parameters $c_{j}$ based on the entries in Table II (a) for the depth subsystem and II (b) for the width subsystem and had volume parameters $V_{j}$ based on the entries in II (c). Seven if-part fuzzy sets described the bullet's weight $X_{1}$ and momentum $X_{2}$ : \{very small (VS), small (SM), medium small (MS), medium (MD), medium large (ML), large (LG), very large (VL) \}. Five then-part fuzzy sets described the armor deformation $\{$ VS, SM, MD, LG, $\mathrm{VL}\}$. Three volume or area values in (c) described the rule uncertainty $\{\mathrm{SM}, \mathrm{MD}, \mathrm{LG}\}$ by fixing the dispersion or width of the then-part sets.

A typical rule (highlighted) in Table II was "if a bullet's weight is Medium Small $\left(X_{1}=M S\right)$ and its momentum is Medium $\left(X_{2}=M D\right)$ then the armor deformation depth is Small $\left(C_{j}=S M\right)$, the width is Very Small $\left(C_{j}=V S\right)$, and the rule uncertainty is Small $\left(V_{j}=S M\right)$." A rule's volume (or dispersion) reflects its uncertainty. The gunshot data tuned the rules in an adaptive SAM function approximation. 


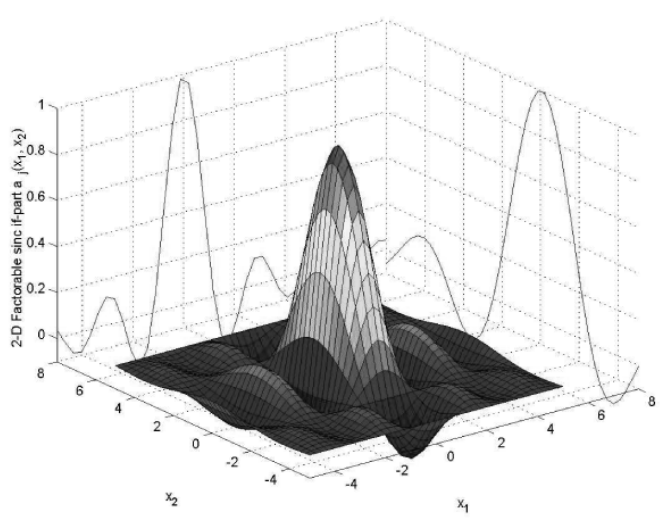

(a) SAMPLE IF-PART SET

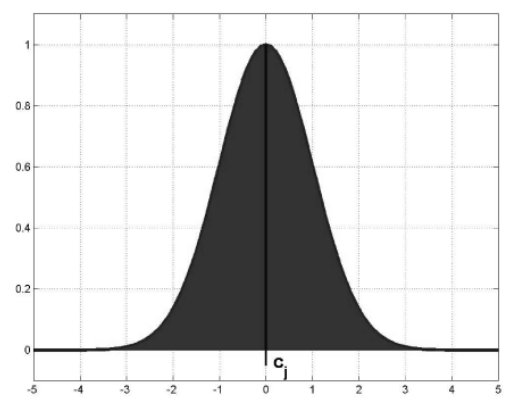

(b) SAMPLE THEN-PART SET

Fig. 3. Sample if-part and then-part fuzzy sets. (a) Joint (product) sinc if-part set function for two-dimensional input case [24]. The joint set function has the factorable form $a_{j}(x)=a_{j}\left(x_{1}, x_{2}\right)=a_{j}^{1}\left(x_{1}\right) \times a_{j}^{2}\left(x_{2}\right)$. The shadows show the scalar sinc set functions $a_{j}^{i}: R \rightarrow R$ for $i=1,2$ that generate $a_{j}: R^{2} \rightarrow R$. (b) Scalar Gaussian then-part set function centered at $c_{j}$.

We applied two scalar-valued additive fuzzy systems [5], [24] $F: R^{n} \rightarrow R^{p}$ (for $p=1$ ) in parallel that used two-dimensional inputs $(n=2)$ to model the depth and width of a bullet-armor impact. These systems approximated some unknown function $f: R^{2} \rightarrow R$ by covering the graph of $f$ with $m$ fuzzy rule patches and averaging patches that overlap. An if-then rule of the form "If $X$ is $A$ then $Y$ is $B$ " defined a fuzzy Cartesian patch $A \times B$ in the input-output space $X \times Y$. The rules could use fuzzy sets of any shape for either their if-part sets $A$ or thenpart sets $B$. This held for the feedforward SAM fuzzy systems discussed below. Their generality further permitted any scheme for combining if-part vector components because all theorems assumed only that the set function mapped to numbers as in $a: R^{n} \rightarrow[u, v]$. Fig. 3 shows a sample two-dimensional if-part set that used a joint factorable sinc function. The general fuzzy approximation theorem allows any choice of if-part sets or thenpart sets for a general additive model and specifically allows any choice of if-part sets for the SAM case (this includes most fuzzy systems in use) [24]. These nonlinear systems can approximate any continuous (or bounded measurable) function on a compact domain [5].

The if-part fuzzy sets $A_{j} \subset R^{n}$ and then-part fuzzy sets $B_{j} \subset$ $R^{p}$ had set functions $a_{j}: R^{2} \rightarrow[0,1]$ and $b_{j}: R \rightarrow[0,1]$ for $n=2$ and $p=1$. An additive fuzzy system [5], [24] summed the "fired" then-part sets $B_{j}^{\prime}$

$$
B(x)=\sum_{j=1}^{m} w_{j} B_{j}^{\prime}=\sum_{j=1}^{m} w_{j} a_{j}(x) B_{j} .
$$

The scaling choice $B_{j}^{\prime}=a_{j}(x) B_{j}$ gave an SAM. The SAM output $F$ was the centroid of $B(x)$ in (1): $F(x)=$ Centroid $(B(x))$.

The shape of if-part sets $A_{j}$ affected how well the feedforward SAM output $F$ approximates a function $f$ and how quickly an adaptive SAM output $F$ approximated the function $f$ when learning tuned the parameters of $A_{j}$ and the centroids $c_{j}$ and volumes $V_{j}$ of the then-part set $B_{j}$ based on input-output samples from $f$. The shape of the then-part sets $B_{j}$ did not affect the first-order behavior of a feedforward SAM output $F$ beyond the effect of the volume $V_{j}$ and centroid $c_{j}$. This held because the SAM output computed a convex-weighted sum of the then-part centroids $c_{j}$ for each vector input $x$

$$
\begin{aligned}
F(x) & =\frac{\sum_{j=1}^{m} w_{j} a_{j}(x) V_{j} c_{j}}{\sum_{j=1}^{m} w_{j} a_{j}(x) V_{j}} \\
& =\sum_{j=1}^{m} p_{j}(x) c_{j}=E[Y \mid X=x]
\end{aligned}
$$

for if-part joint set function $a_{j}: R^{n} \rightarrow[0,1]$ that defined the if-part set $A_{j} \subset R^{n}$, rule weights $w_{j} \geq 0, p_{j}(x) \geq 0$, and $\sum_{j=1}^{m} p_{j}(x)=1$ for each $x \in R^{2}$. Fig. 4 (a) and (c) are examples of the SAM output $F$ based on the rules in Table II with two-dimensional joint factorable sinc if-part set functions. The convex coefficient

$$
p_{j}(x)=\frac{w_{j} a_{j}(x) V_{j}}{\sum_{i=1}^{m} w_{i} a_{i}(x) V_{i}}
$$

depended on then-part set $B_{j}$ only through its volume or area $V_{j}$ (and perhaps through its rule weight $w_{j}$ ).

The fuzzy output $F(x)$ in (2) equals the conditional expectation $E[Y \mid X=x]$ in (3) because the then-part set functions $b_{j}$ are non-negative and have finite volume (area) and because $F(x)$ is the centroid of $B(x)$. Appendix B shows that these two conditions give a well-defined conditional probability density function $p(y \mid x)$ in $F(x)=\int_{-\infty}^{\infty} y p(y \mid x) d y$ [5]. So the SAM output describes the first-order behavior of the fuzzy system and does not depend on the shape of the then-part sets $B_{j}$. But the shape of $B_{j}$ did affect the second-order uncertainty or conditional variance $V[Y \mid X=x]$ of the SAM output $F(x)$ [5]

$$
V[Y \mid X=x]=\sum_{j=1}^{m} p_{j}(x) \sigma_{B_{j}}^{2}+\sum_{j=1}^{m} p_{j}(x)\left[c_{j}-F(x)\right]^{2}
$$




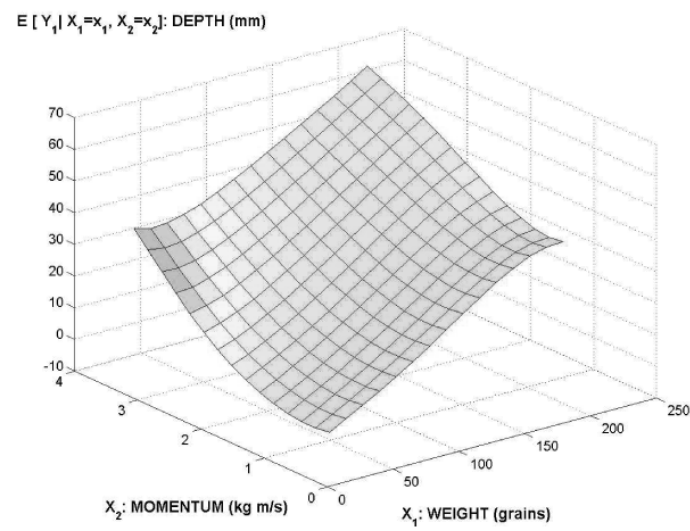

(a) DEPTH: $F_{1}\left(x_{1}, x_{2}\right)=E\left[Y_{1} \mid X_{1}=x_{1}, X_{2}=x_{2}\right]$

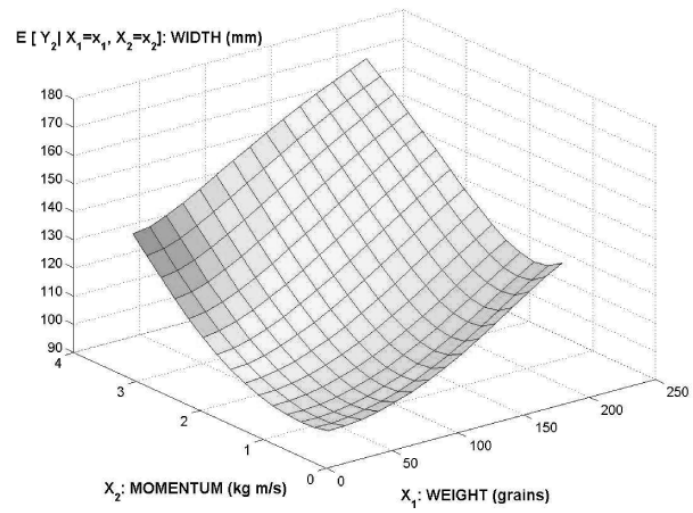

(c) WIDTH: $F_{2}\left(x_{1}, x_{2}\right)=E\left[Y_{2} \mid X_{1}=x_{1}, X_{2}=x_{2}\right]$

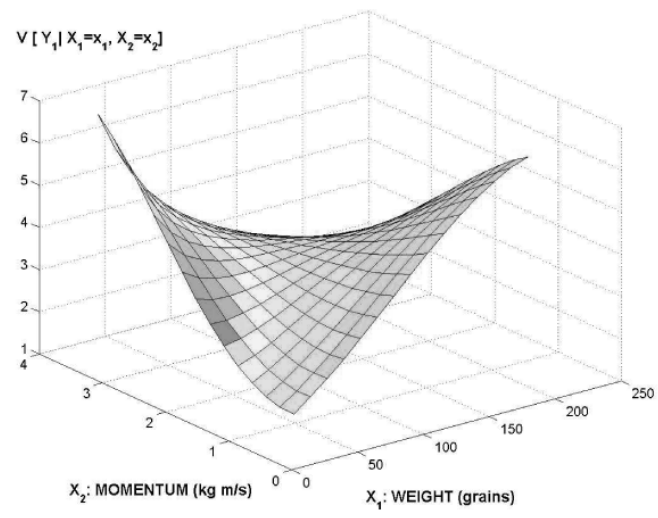

(b) $V\left[Y_{1} \mid X_{1}=x_{1}, X_{2}=x_{2}\right]$

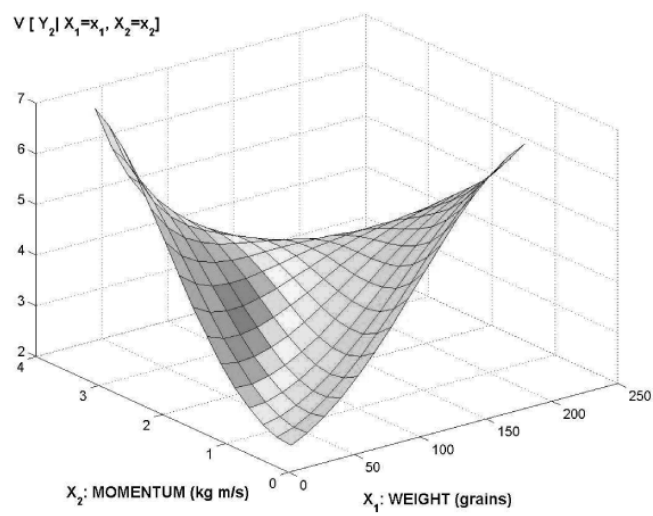

(d) $V\left[Y_{2} \mid X_{1}=x_{1}, X_{2}=x_{2}\right]$

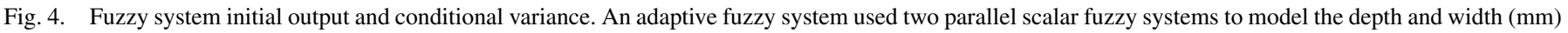

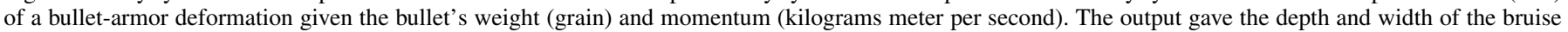

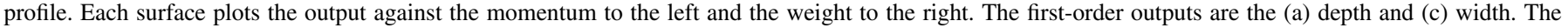

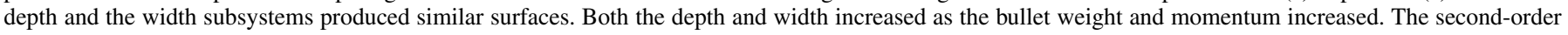

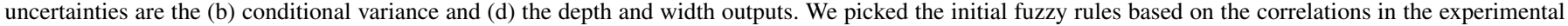

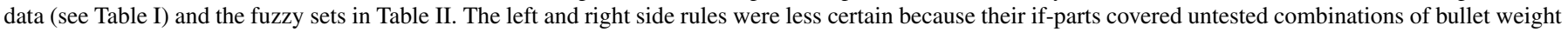
and momentum. So their then-parts had larger set variances and gave larger conditional variances.

where $\sigma_{B_{j}}^{2}$ is the then-part set variance

$$
\sigma_{B_{j}}^{2}=\int_{-\infty}^{\infty}\left(y-c_{j}\right)^{2} p_{B_{j}}(y) d y
$$

where $p_{B_{j}}(y)=b_{j}(y) / V_{j}$ is an integrable probability density function and $b_{j}: R \rightarrow[0,1]$ is the integrable scalar set function of then-part set $B_{j}$. Figs. 4(b) and (d) show examples of the conditional variance $V[Y \mid X=x]$ based on the rules in Table II with Gaussian then-parts. The first term on the right side of (5) gave an input-weighted sum of the then-part set uncertainties. The second term measured the interpolation penalty that resulted from computing the SAM output $F(x)$ in (2) as the weighted sum of centroids. The second-order structure of a fuzzy system's output depended crucially on the size and shape of the then-part sets $B_{j}$.

Learning tuned the volumes $V_{j}$ and centroids $c_{j}$ of the thenpart sets $B_{j}$ in our adaptive function-approximation. The adaptive SAM fuzzy system learned from data with learning laws that updated the fuzzy rules so as to reduce the squared error of the function approximation. The two-dimensional joint factorable sinc if-part [see Fig. 3(a)] had learning laws that updated the two-dimensional vector center $m_{j}$ and dispersion (or width) $d_{j}$ parameters

$$
\begin{aligned}
m_{j}^{k}(t+1)= & m_{j}^{k}(t)+\mu_{t} \varepsilon_{t} \frac{p_{j}(x)}{a_{j}(x)} \frac{a_{j}(x)}{a_{j}^{k}\left(x_{k}\right)}\left(c_{j}-F(x)\right) \\
& \times\left(a_{j}(x)-\cos \left(\frac{x-m_{j}^{k}(t)}{d_{j}(t)}\right)\right) \frac{1}{x-m_{j}^{k}(t)} \\
d_{j}^{k}(t+1)= & d_{j}^{k}(t)+\mu_{t} \varepsilon_{t} \frac{p_{j}(x)}{a_{j}(x)} \frac{a_{j}(x)}{a_{j}^{k}\left(x_{k}\right)}\left(c_{j}-F(x)\right) \\
& \times\left(a_{j}(x)-\cos \left(\frac{x-m_{j}^{k}(t)}{d_{j}(t)}\right)\right) \frac{1}{d_{j}^{k}(t)}
\end{aligned}
$$

where $\mu_{t}$ was a learning rate at iteration $t$ and $\varepsilon_{t}$ was the approximation error or the difference between the fuzzy output $F(x)$ 
and the approximand $f$. The Gaussian then-part parameters had learning laws that updated the scalar centroid $c_{j}$ and volume $V_{j}$

$$
\begin{aligned}
c_{j}(t+1) & =c_{j}(t)+\mu_{t} \varepsilon_{t}(x) p_{j}(x) \\
V_{j}(t+1) & =V_{j}(t)-\mu_{t} \varepsilon_{t}(x) \frac{p_{j}(x)}{V_{j}}\left[c_{j}-F(x)\right]
\end{aligned}
$$

where the volume or area of a scalar Gaussian then-part set was a function of the standard deviation: $V_{j}=\sqrt{2 \pi \sigma_{B_{j}}^{2}}=\sigma_{B_{j}} \sqrt{2 \pi}$. This related the dispersion or width of a then-part set to its volume and so related the volume parameter $V_{j}$ to the set variance $\sigma_{B_{j}}^{2}$ that contributed to the conditional variance.

Fuzzy systems $F: R^{n} \rightarrow R^{p}$ suffer from rule explosion in high dimensions. A fuzzy system $F$ needs on the order of $k^{n+p-1}$ rules to cover the graph and thus to approximate a vector function $f: R^{n} \rightarrow R^{p}$. Optimal rules can help deal with the exponential rule explosion. Lone or local mean-squared optimal rule patches cover the extrema of the approximand $f$ : They patch the bumps [5]. Better learning schemes move rule patches to or near extrema and then fill in between extrema with extra rule patches if the rule budget allows.

\section{BULLET-ARMOR IMPACT EXPERIMENTS}

\section{A. Experimental Setup}

Two experimental setups measured the bullet-armor impacts' depths and widths against a gelatin block backing in the Orange County Indoor Shooting Range. The first setup used donated commercial armor to produce the deformation data. It fixed the bullet caliber $(9 \mathrm{~mm})$ and varied the distance between the target and the handgun. The distances were 5,7 , and 10 yards. These three short distances produced three measurably different bullet impacts because air friction quickly slows a bullet after it leaves the gun barrel.

The second setup used generic armor that we made from eight layers of Kevlar fabric to produce the deformation data. It varied both the bullet caliber and the handguns' barrel lengths and fixed the distance ( 5 feet) between the target and the handguns. The setup used $.22, .38, .40$, and .45 caliber bullets. This choice of bullets gave a monotonic increase in bullet diameter and weight. We also used .357 magnum bullets that had weight similar to .38 caliber bullets and momentum similar to .45 caliber bullets due to higher speeds. A .44 magnum bullet penetrated the eight-layer generic armor. So we had no deformation data for the .44 magnum bullets. Hexcel Schwebel donated the Style 713 Aramid fabric that had 1000 deniers of Kevlar 29 fibers in plain weave.

The gel-backed experiments used $10 \%$ gelatin blocks to simulate tissue that backed the armor. Fig. 5 shows a sample gelatin block. The gelatin blocks consisted of one part Type 250 A Ordnance Gelatin from Kind \& Knox Gelatin and nine parts water by weight. We weighed the water-filled mold to find the $10 \%$ weight for the gelatin powder and weighed the mold while we added water to achieve the 1:9 ratio. Slowly stirring water into the gelatin powder reduced bubble formation. The mixture required refrigeration for $24 \mathrm{~h}$ to prevent spoilage while the powder hydrated. This further reduced air bubble formation. A warm water bath of about $40^{\circ} \mathrm{C}$ melted the mixture and prevented denaturing the gelatin. A cold water bath set the melted gelatin in molds that measured about $40 \mathrm{~cm}$ long by $30 \mathrm{~cm}$ wide by $12 \mathrm{~cm}$ thick.

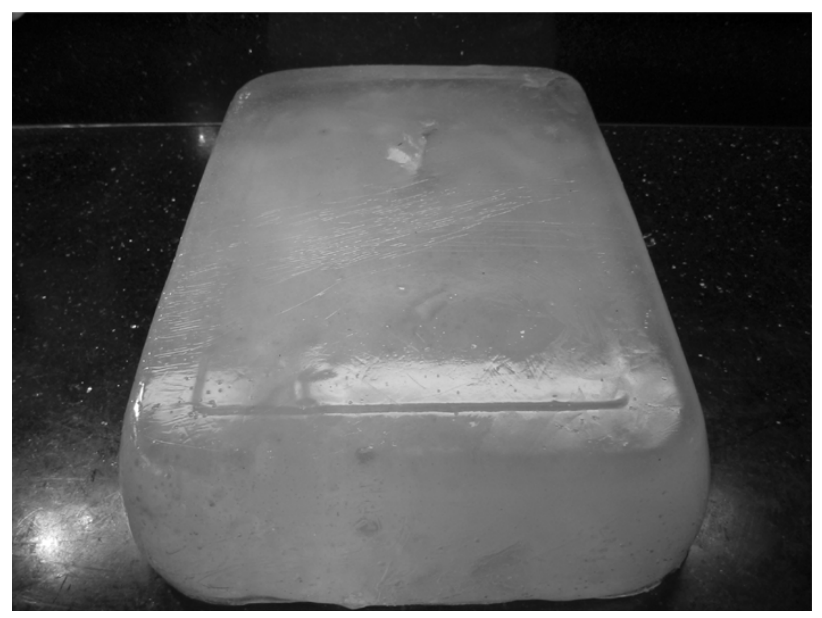

Fig. 5. Sample $10 \%$ ordnance gelatin block. A target consisted of a generic armor-clad gelatin block. The gel block was the tissue simulant.

\section{TABLE III}

Average Bullet SpeEds For the Available Combinations OF BULLET WEIGHT (CALIBER) AND BARREL LENGTH

\begin{tabular}{l|r|r|r|r|r|r|r}
\hline & & .22 & .38 & .40 & .45 & $.357 \mathrm{mag}$ & $.44 \mathrm{mag}$ \\
\hline & WEIGHT & 40 & 150 & 165 & 185 & 158 & 240 \\
\hline SPEED & Barrel 1 & 977 & 722 & 937 & 808 & 1135 & 1263 \\
\hline & Barrel 2 & 1059 & 751 & N/A & 897 & N/A & N/A \\
\hline
\end{tabular}

Refrigeration hardened the gelatin blocks in $48-72 \mathrm{~h}$ and ensured a uniform temperature of about $4^{\circ} \mathrm{C}$ in the blocks. The refrigerator ran for $24 \mathrm{~h}$ before use to ensure that its temperature equilibrated in a range above freezing and below $4^{\circ} \mathrm{C}$. This kept a gelatin block's temperature low while avoiding damage from ice crystals. We used ice chests to transport the gelatin blocks to and from the shooting range.

A BB shot calibrated each gelatin block before use by giving BB penetration at known temperatures. A model 760B BB Repeater Air Rifle from Crossman Air Guns can shoot a 5.5-grain BB at between 530-590 feet per second ( $\mathrm{ft} / \mathrm{s})$ with ten pumps. An outdoor thermometer measured the gelatin temperature before using the blocks.

We measured the bullet velocity at 12 feet or 3 yards and separate from the impact experiments. The ProChrono Plus optical chronometer from Competition Electronics complicated shot placement in the indoor shooting range. It required a separation of at least 10-15 feet from the handguns to prevent interference from the propellant smoke. The indoor lighting dictated a $12-\mathrm{ft}$ separation between the chronometer and the handguns and a 58 -inch separation between the chronometer and the floor. This was because the optical sensors required some minimal amount of light to detect a bullet's shadow as the bullet passed. The lack of a pistol holder allowed marksmanship to further complicate shot placement in the experiments.

The shooting range provided reloaded ammunition with fullcopper-jacketed bullets. The 9-mm bullets weighed 115 grains on average. The mean velocity was $1216 \mathrm{ft} / \mathrm{s}$ for bullets from the same ammunition box. Table III shows the mean bullet speeds for each combination of bullet caliber and barrel length. The .22 caliber bullets had one mean weight (40 grains) and two different speeds ( $977 \mathrm{ft} / \mathrm{s}$ and $1059 \mathrm{ft} / \mathrm{s}$ on average). We used the 
TABLE IV

LINEAR REGRESSION STATISTICS FOR THE GELATIN-BACKED BULLET-ARMOR IMPACT EXPERIMENTS

\begin{tabular}{|c|c|c|c|c|c|}
\hline $\begin{array}{r}\text { DEPTH } \\
\text { REGRESSION }\end{array}$ & $R^{2}$ & $\beta_{0}$ & $\beta_{1}$ & $\begin{array}{c}\mathbf{H}_{0}: \beta_{1}=0 \\
t(p \text {-value })\end{array}$ & $\begin{array}{l}\mathbf{H}_{0}: \beta_{0}, 1=0 \\
F(p \text {-value })\end{array}$ \\
\hline WEIGHT (1) & 0.880 & 5.385 & 0.280 & $19.892(p<0.001)$ & $395.702(p<0.001)$ \\
\hline (2) & 0.893 & 5.424 & 0.283 & $19.210(p<0.001)$ & $369.022(p<0.001)$ \\
\hline MOMENTUM (1) & 0.741 & 9.443 & 13.718 & $12.415(p<0.001)$ & $154.135(p<0.001)$ \\
\hline (2) & 0.875 & 4.838 & 16.700 & $17.549(p<0.001)$ & $307.966(p<0.001)$ \\
\hline KINETIC ENERGY (1) & 0.474 & 20.225 & 0.066 & $6.972(p<0.001)$ & $48.606(p<0.001)$ \\
\hline (2) & 0.786 & 7.018 & 0.118 & $12.694(p<0.001)$ & $161.138(p<0.001)$ \\
\hline SPEED (1) & 0.089 & 79.885 & -0.124 & $-2.298(p=0.025)$ & $5.280(p=0.025)$ \\
\hline (2) & 0.278 & 129.560 & -0.314 & $-4.115(p<0.001)$ & $16.929(p<0.001)$ \\
\hline TARGET DISTANCE & 0.415 & 29.328 & -1.203 & $-4.453(p<0.001)$ & $19.826(p<0.001)$ \\
\hline $\begin{array}{r}\text { WIDTH } \\
\text { REGRESSION }\end{array}$ & $R^{2}$ & $\beta_{0}$ & $\beta_{1}$ & $\begin{array}{c}\mathbf{H}_{0}: \beta_{1}=0 \\
t(p \text {-value })\end{array}$ & $\begin{array}{l}\mathbf{H}_{0}: \beta_{0}, 1=0 \\
F(p \text {-value })\end{array}$ \\
\hline WEIGHT (1) & 0.865 & 84.816 & 0.421 & $18.580(p<0.001)$ & $345.214(p<0.001)$ \\
\hline (2) & 0.882 & 84.900 & 0.428 & $18.170(p<0.001)$ & $330.141(p<0.001)$ \\
\hline MOMENTUM (1) & 0.745 & 90.295 & 20.870 & $12.566(p<0.001)$ & $157.898(p<0.001)$ \\
\hline (2) & 0.906 & 82.612 & 25.844 & $20.589(p<0.001)$ & $423.899(p<0.001)$ \\
\hline KINETIC ENERGY (1) & 0.482 & 106.478 & 0.101 & $7.094(p<0.001)$ & $50.328(p<0.001)$ \\
\hline (2) & 0.851 & 84.692 & 0.186 & $15.842(p<0.001)$ & $250.978(p<0.001)$ \\
\hline SPEED (1) & 0.079 & 194.170 & -0.177 & $-2.153(p=0.036)$ & $4.636(p=0.036)$ \\
\hline (2) & 0.220 & 258.890 & -0.424 & $-3.521(p=0.001)$ & $12.395(p=0.001)$ \\
\hline TARGET DISTANCE & 0.004 & 58.162 & 0.1082 & $0.340(p<0.001)$ & $0.115(p=0.737)$ \\
\hline $\begin{array}{r}\text { DEPTH } \\
\text { REGRESSION } \\
\end{array}$ & $R^{2}$ & $\begin{array}{c}\beta_{0} \\
t(p \text {-value })\end{array}$ & $\begin{array}{c}\beta_{1} \\
t(p \text {-value }) \\
\end{array}$ & $\begin{array}{c}\beta_{2} \\
t(p \text {-value }) \\
\end{array}$ & $\begin{array}{l}\mathbf{H}_{0}: \beta_{0,1,2}=0 \\
F(p \text {-value })\end{array}$ \\
\hline $\begin{array}{l}\text { WEIGHT AND (1) } \\
\text { MOMENTUM } \\
\text { (2) }\end{array}$ & 0.896 & $\begin{array}{c}5.550 \\
2.616(p=0.012) \\
4.913 \\
2.225(p=0.031)\end{array}$ & $\begin{array}{c}0.304 \\
7.903(p<0.001) \\
0.207 \\
2.988(p=0.005) \\
\end{array}$ & $\begin{array}{c}-1.361 \\
-0.663(p=0.510) \\
4.625 \\
1.119(p=0.270)\end{array}$ & $\begin{array}{l}F=196.020 \\
p<0.001 \\
F=186.190 \\
p<0.001\end{array}$ \\
\hline $\begin{array}{l}\text { WEIGHT AND (1) } \\
\text { KINETIC ENERGY } \\
\text { (2) }\end{array}$ & 0.881 & $\begin{array}{c}5.586 \\
2.638(p=0.011) \\
4.845 \\
2.177(p=0.035)\end{array}$ & $\begin{array}{c}0.293 \\
13.494(p<0.001) \\
0.247 \\
6.782(p<0.001)\end{array}$ & $\begin{array}{c}-0.006 \\
-0.800(p=0.427) \\
0.018 \\
1.096(p=0.279)\end{array}$ & $\begin{array}{l}F=196.851 \\
p<0.001 \\
F=185.965 \\
p<0.001\end{array}$ \\
\hline $\begin{array}{l}\text { MOMENTUM AND (1) } \\
\text { KINETIC ENERGY }\end{array}$ & 0.897 & $\begin{array}{c}5.574 \\
2.704(p=0.009) \\
5.348 \\
2.418(p=0.020) \\
\end{array}$ & $\begin{array}{c}31.388 \\
13.943(p<0.001) \\
29.484 \\
6.810(p<0.001) \\
\end{array}$ & $\begin{array}{c}-0.112 \\
-8.305(p<0.001) \\
-0.097 \\
-3.015(p=0.004)\end{array}$ & $\begin{array}{l}F=208.555 \\
p<0.001 \\
F=186.838 \\
p<0.001\end{array}$ \\
\hline $\begin{array}{r}\text { WIDTH } \\
\text { REGRESSION } \\
\end{array}$ & $R^{2}$ & $\begin{array}{c}\beta_{0} \\
t(p \text {-value })\end{array}$ & $\begin{array}{c}\beta_{1} \\
t(p \text {-value })\end{array}$ & $\begin{array}{c}\beta_{2} \\
t(p \text {-value })\end{array}$ & $\begin{array}{l}\mathbf{H}_{0}: \beta_{0,1,2}=0 \\
F(p \text {-value })\end{array}$ \\
\hline $\begin{array}{l}\text { WEIGHT AND (1) } \\
\text { MOMENTUM } \\
\text { (2) }\end{array}$ & 0.865 & $\begin{array}{c}84.846 \\
24.742(p<0.001) \\
82.646 \\
26.075(p<0.001)\end{array}$ & $\begin{array}{c}0.425 \\
6.846(p<0.001) \\
0.093 \\
0.932(p=0.356)\end{array}$ & $\begin{array}{c}-0.240 \\
-0.073(p=0.942) \\
20.438 \\
-0.073(p=0.001)\end{array}$ & $\begin{array}{l}F=169.430 \\
p<0.001 \\
F=211.752 \\
p<0.001\end{array}$ \\
\hline $\begin{array}{l}\text { WEIGHT AND (1) } \\
\text { KINETIC ENERGY } \\
\text { (2) }\end{array}$ & 0.907 & $\begin{array}{c}84.967 \\
24.804(p<0.001) \\
82.342 \\
25.661(p<0.001) \\
\end{array}$ & $\begin{array}{c}0.431 \\
12.261(p<0.001) \\
0.267 \\
5.086(p<0.001) \\
\end{array}$ & $\begin{array}{c}-0.004 \\
-0.370(p=0.713) \\
0.078 \\
3.361(p=0.002)\end{array}$ & $\begin{array}{l}F=169.917 \\
p<0.001 \\
F=209.355 \\
p<0.001\end{array}$ \\
\hline $\begin{array}{l}\text { MOMENTUM AND (1) } \\
\text { KINETIC ENERGY }\end{array}$ & 0.883 & $\begin{array}{c}84.603 \\
26.588(p<0.001) \\
82.866 \\
26.139(p<0.001)\end{array}$ & $\begin{array}{c}46.864 \\
13.486(p<0.001) \\
32.226 \\
5.192(p<0.001)\end{array}$ & $\begin{array}{c}-0.165 \\
-7.914(p<0.001) \\
-0.048 \\
-1.050(p=0.300)\end{array}$ & $\begin{array}{l}F=200.376 \\
p<0.001 \\
F=212.991 \\
p<0.001\end{array}$ \\
\hline
\end{tabular}

See the text below for more details.

data in Table III (except the .44 magnum bullets) for the weight and momentum that trained the fuzzy system.

\section{B. Experimental Results}

The gelatin-backed bullet-armor experiments found that a bullet's impact depth correlated with its distance to target $d$ with the first setup and found that depth correlated with bullet properties that included the mean weight $m$, momentum $p=m v$, and kinetic energy $1 / 2 m v^{2}$ in decreasing order with the second setup. Depth correlation with kinetic energy was much less than the correlations with weight or momentum. Impact depth also correlated with combinations of weight, momentum, and kinetic energy. The impact width similarly correlated with the bullet properties except distance. The impact depth and width correlated very little with a bullet's mean speed $v$. This held because the .45 caliber bullet-armor impacts were deeper and wider than both the .22 and .38 caliber impacts when the .22 caliber bullets were faster and the .38 caliber bullets were slower.

Table IV shows the regression statistics. The statistics were based on two subsets of the experimental data: Dataset (1) was 


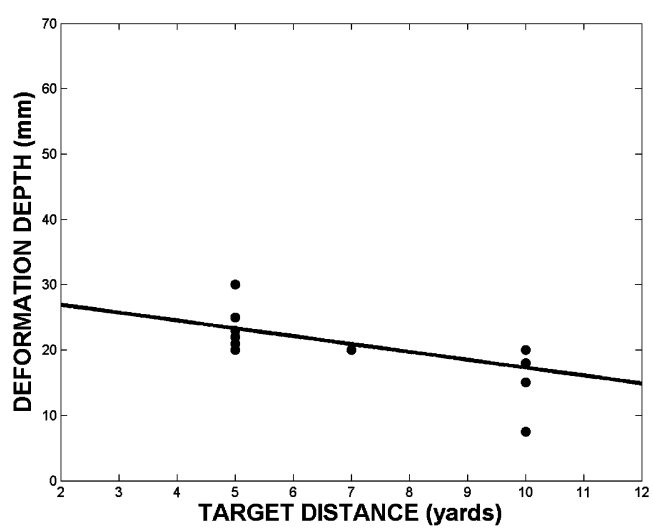

(a) DEPTH

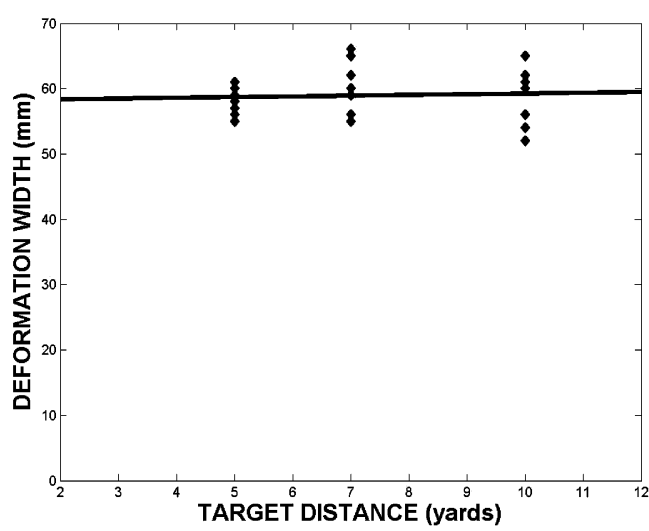

(b) WIDTH

Fig. 6. Impact data from the first gelatin-backed bullet-armor experiments. (a) Impact depth correlates with distance to target. The correlation was $R^{2}=0.415$ and linear regression gave $y_{1}=29.328-1.203 x$ with $p$-value $<0.001$ where $x$ was the distance in yards and $y_{1}$ was the deformation depth in mm. (b) Impact width correlates poorly with distance: $R^{2}=0.004$. The regression equation was $y_{2}=58.162+0.1082 x$. Note that the regression line is nearly horizontal.

complete and Dataset (2) excluded the .357 magnum data. The key results held for both datasets. First was that deformation depth and width correlated with a bullet's weight, momentum, and kinetic energy while speed correlated little. Second was that kinetic energy had a weaker correlation with deformation than either weight or momentum. A bullet's weight monotonically increased with its caliber in Dataset (2) and could represent caliber by excluding the magnum data. Dataset (2) had stronger correlations (larger $R^{2}$ ) than Dataset (1). Deformation correlated with momentum more than it correlated with weight in Dataset (2).

Regression analysis fit the experimental data to a straight line. The simple linear model used functions of $x$ and had smaller $p$-values than quadratic and cubic models while the quadratic and cubic models had marginally larger $R^{2}$ values. The $R^{2}$ measured the strength of the correlation between the dependent and the independent variables. The first gel-backed experiments used a regression equation of the form

$$
y=\beta_{0}+\beta_{1} x
$$

where $y$ was the deformation depth or width in millimeters ( $\mathrm{mm}$ ) and $x$ was the distance between the target and the handgun in yards.

The second gel-backed experiments used the simple linear regression (11) to model how deformation depends on the individual bullet properties such as mean weight, speed, momentum, and kinetic energy. Multiple linear regression modeled how deformation depends on weight, momentum, and kinetic energy. The multiple regression equation had the form

$$
y=\beta_{0}+\beta_{1} x_{1}+\beta_{2} x_{2}
$$

where $y$ was the deformation depth or width in $\mathrm{mm}$ and $x_{1}$ and $x_{2}$ were the weight in grains, momentum in kilograms meter per second $(\mathrm{kg} \mathrm{m} / \mathrm{s})$, or kinetic energy in kilograms meter squared per second squared $\left(\mathrm{kg} \mathrm{m} / \mathrm{s}^{2}\right)$.

We applied the simple linear model in (11) to test whether bullet deformation correlated with each of a bullet's properties. The null hypothesis $\mathbf{H}_{0}: \beta_{1}=0$ stated that the slope $\beta_{1}$ of the regression line in (11) was zero and thus the impact deformation's depth and width (dependent variables) did not vary with a bullet's weight, momentum, kinetic energy, speed, or distance to target (independent variables). The $p$-value measures the credi- bility of $\mathbf{H}_{0}$. A statistical test rejects the null hypothesis $\mathbf{H}_{0}$ at a significance level $\alpha$ if the $p$-value is less than that significance level: Reject $\mathbf{H}_{0}$ if $p$-value $<\alpha$. The test rejected the null hypothesis $\mathbf{H}_{0}$ at the standard significance levels $\alpha=0.05$ and $\alpha=0.01$ because $p$-value $<0.001$.

We applied the multiple regression in (12) for combinations of a bullet's properties such as weight and momentum and tested the null hypothesis $\mathbf{H}_{0}: \beta_{i}=0$ for $i=0,1,2$ that all the parameters were statistically insignificant. This tested whether the deformation's depth and width varied with the combination of a bullet's weight and momentum. The test found that the regression coefficient for weight was statistically more significant than the coefficients for momentum or kinetic energy (see Table IV). This helped guide our choice of weight and momentum as the inputs of the fuzzy system.

Fig. 6 shows the depth and the width of the bullet-armor deformation after each impact in the first gelatin-backed experiments. The deformation depth decreased as target distance increased. Linear regression (see Table IV) gave $R^{2}=0.415$, regression equation $y_{1}=29.328-1.203 x$, and $p$-value $<0.001$ where $x$ was the distance in yards and $y_{1}$ was the deformation depth in $\mathrm{mm}$. The width $y_{2}$ did not appear to vary with target distance for $R^{2}=0.004, y_{2}=58.162+0.1082 x$, and $p$-value $<0.001$. These statistics suggested a nonzero slope but almost no correlation for $R^{2}=0.004$. The correlations between deformation and target distance also held for between deformation and momentum because bullet weight was approximately constant and velocity was a monotonic function of distance. The limited number of data points was due to the availability of the donated armor. The shots should overlap as little as possible and avoid the armor panel edges for consistency. Marksmanship further decreased the number of shots as distance increased.

Fig. 7 shows the (a) complete deformation depth data and the (b) complete width data of the bullet-armor deformation as a function of bullet weight and momentum in the second gelatin-backed experiments. The regression planes suggested that depth correlated with bullet momentum more than weight and that width correlated with weight more than momentum. Excluding the magnum data in (c) and (d) changed the depth regression planes: It suggested that deformation depth correlated with both a bullet's weight and momentum. The correlation strengths were $R^{2}=0.881$ for the depth and $R^{2}=0.865$ 


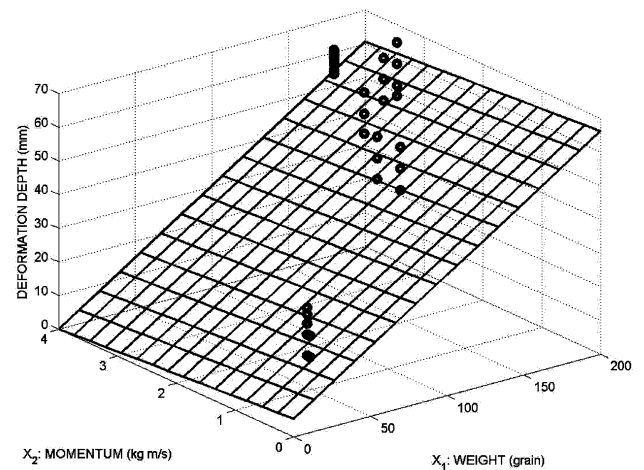

(a) DEPTH

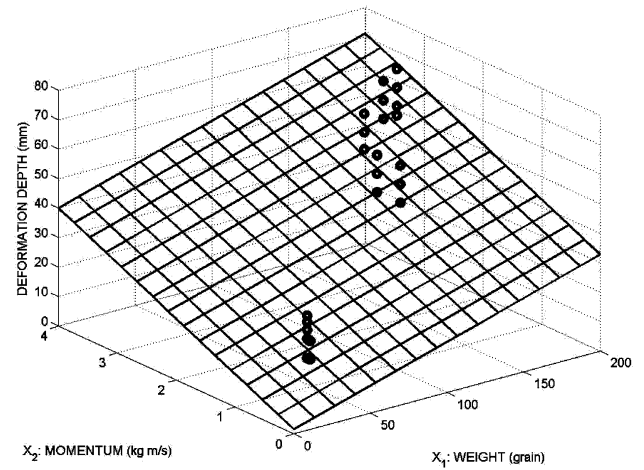

(c) DEPTH EXCLUDE MAGNUM

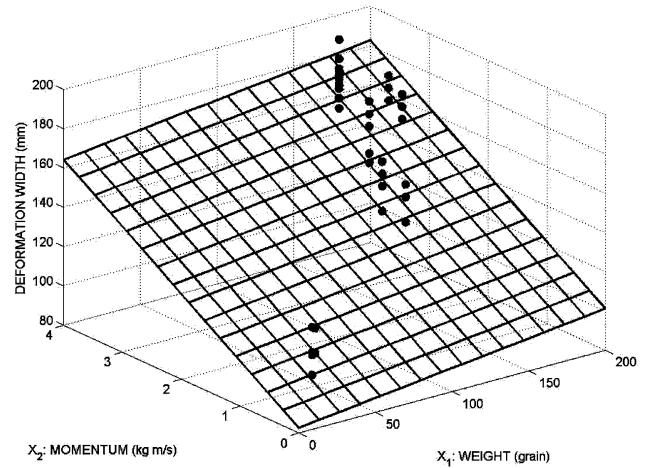

(b) WIDTH

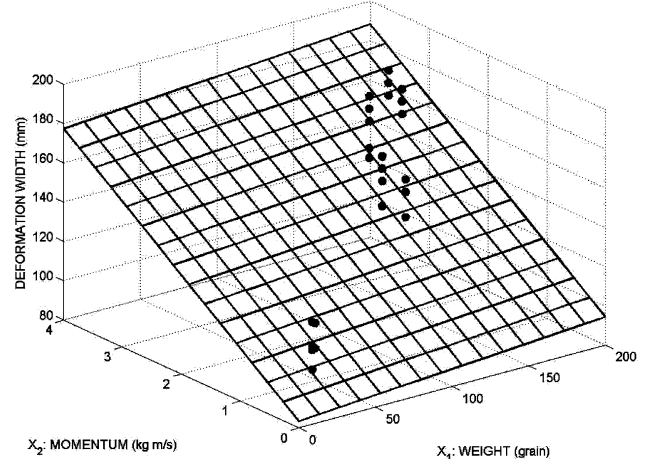

(d) WIDTH EXCLUDE MAGNUM

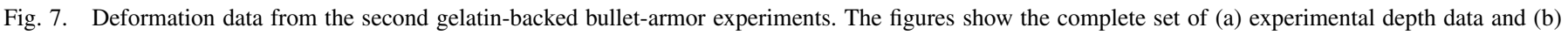

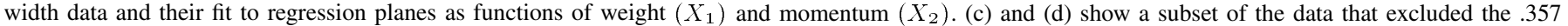

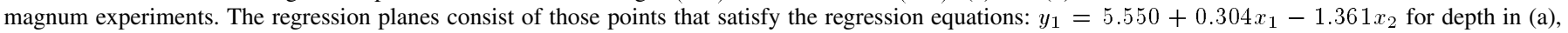

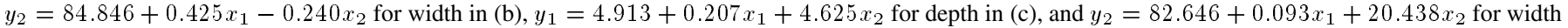
in (d).

for the width using the complete set of experimental data. The depth equation was $y_{1}=5.550+0.304 x_{1}-1.361 x_{2}$ where $x_{1}$ was bullet weight (grain) and $x_{2}$ was momentum $(\mathrm{kg} \mathrm{m} / \mathrm{s})$. The width equation was $y_{2}=84.846+0.425 x_{1}-0.240 x_{2}$. The test statistics for depth correlation were $F=196.020$ and $p$-value $<0.001$. The test statistics for width correlation were $F=169.430$ and $p$-value $<0.001$. The test rejected the null hypothesis $\mathbf{H}_{0}$ at the standard significance levels $\alpha=0.05$ and $\alpha=0.01$.

The experiments used five bullet calibers $[.22, .38, .40$, and .45 caliber and .357 magnum (see Fig. 2)] and two different speeds [such as on average $808 \mathrm{ft} / \mathrm{s}$ and $897 \mathrm{ft} / \mathrm{s}$ for the .45 (see Table III)] per caliber to produce 56 sets of input-output data. This gave the sparse sampling of the input space in Fig. 7.

\section{BASEBALL IMPACT EXPERIMENTS}

\section{A. Experimental Setup}

Two putty-backed experimental setups compared the baseball impacts to bullet-armor impacts. The baseball setup measured baseball impacts on tubs of Oatey's Plumber's Putty at the Homerun Park in Anaheim, California. The outdoor batting cage used pitching machines that threw baseballs at 40 , 50, 60, 70, 80, and $90 \mathrm{mph}$. The chronometer used a baseball's passing shadow under the sun to measure the baseball's speed. We placed the chronometer approximately a half foot from the putty target. The putty-filled tubs were approximately $3-5 \mathrm{ft}$

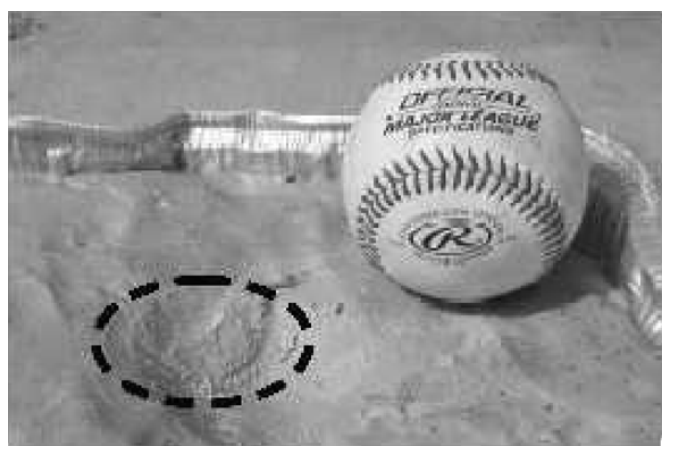

Fig. 8. Regulation baseball and a crater of its impact. Pitching machines threw baseballs at tubs of plumber's putty. A chronograph measured the speed of each baseball. The baseball speeds were approximately 40, 50, 60, 70, 80, and $90 \mathrm{mph}$.

from the pitching machines. Each tub consisted of at least 15 pounds of the putty. Fig. 8 shows one sample deformation that a baseball made in putty.

The bullet-armor setup shot bullets at putty-backed soft body armor. The experiments shot $.22, .38, .40$, and .45 caliber bullets and .357 magnum and .44 magnum bullets. The armor was the Superfeatherlite model from Second Chance. The target was $5 \mathrm{ft}$ from the handguns. Fig. 9 shows the depths of the putty deformations from baseball impacts next to the depths of the putty deformations from bullet-armor impacts. The deformations deepened as baseball speeds increased and as bullet cal- 


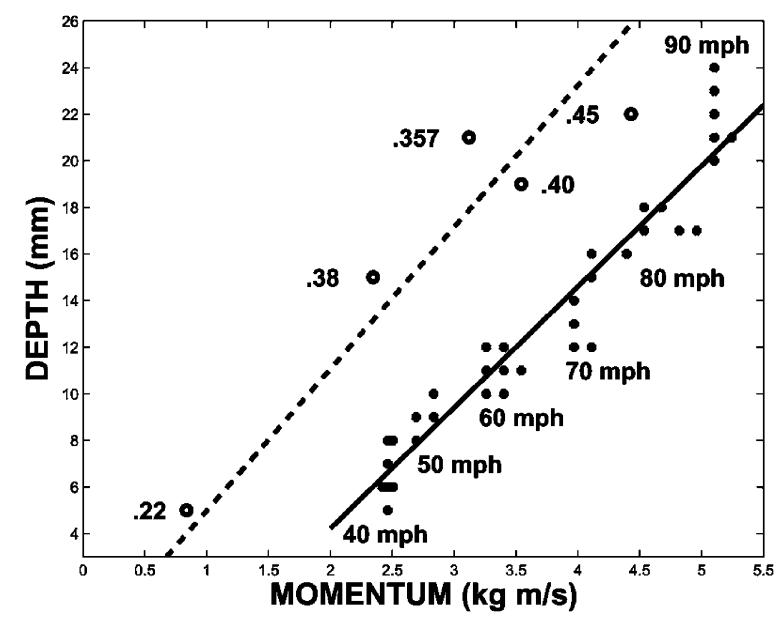

Fig. 9. Baseball and bullet impact depth in plumber's putty versus momentum. The baseball impact depth correlated with baseball momentum $R^{2}=0.93$ and $p$-value $<0.001$ for the null hypothesis: $\beta_{1}=0$. The solid line on the right is the regression line for the baseball impacts (blue dots) $y=-6.155+5.188 x$ where $x$ is baseball momentum and $y$ is putty deformation depth. Only two data points fell outside of the $95 \%$ confidence bounds. Bullet-armor impact depths correlated with bullet momentum $R^{2}=0.97$. The green dashed line on the left is the regression line for the bullet-armor impacts (green circles) $y=2.124+$ $4.766 x$ where $x$ is bullet momentum and $y$ is depth. The two regression lines have the similar slope $\beta_{1} \approx 5$. A multiple regression analysis with dummy variables (Gujarati-Chow test) could not reject the null hypothesis $\mathbf{H}_{0}: \beta_{1}$ (baseball) $=\beta_{1}$ (armor) for the test statistics $t=0.855$ and $p$-value $=0.396$. So the test retained the null hypothesis that the two types of impacts had the same slope.

iber increased. The baseball impact experiments used regulation baseballs (see Fig. 8) to produce at least ten data points for each of the six different speeds. The putty deformed and recorded each impact. We plotted the impact depth against baseball momentum in Fig. 9 to better compare with bullet-armor impact data because the gelatin-backed bullet-armor experiments found that momentum correlated better with deformation depth than it correlated with weight or speed alone. Plotting the deformation depth against baseball momentum preserved the proportion of plotting depth against speed for constant baseball weight.

\section{B. Experimental Results}

The baseball experiments compared bullet-armor impacts to baseball impacts in two ways: Deformation depth in putty and the slopes of the fitted regression lines. The first way compared how the two types of projectile-dented putty deformations differed. Baseball impacts and bullet-armor impacts had similar depths in Oatey's Plumber's Putty.

Table V compared the deformation depths that baseball impacts and bullet-armor impacts produced. For instance: The mean impact depth was $21.6 \mathrm{~mm}$ for 90 -mph baseballs and the bullet-armor impact depth was $21 \mathrm{~mm}$ for a .357 magnum bullet and $22 \mathrm{~mm}$ for a .45 caliber bullet. The .44 magnum bullet-armor impact deformed the putty to a depth of $40 \mathrm{~mm}$ that was about twice the effect of the fastest baseball available so had no comparable highspeed baseball impact.

The similarity of impact depths suggested that handgun shots on soft body armor would feel like baseball impacts without armor. Fast-baseball impact depths were comparable to bulletarmor impact depths: Getting shot with a .22 caliber bullet when wearing soft body armor resembles getting hit in the chest with
TABLE V

Baseballs Deformed Plumber's Putty Similar to Handgun Bullets.

\begin{tabular}{l|r|r|r|r|r|r}
\hline Bullet Caliber & .22 & .38 & .40 & .357 & .45 & .44 \\
\hline Depth (mm) & 5 & 15 & 19 & 21 & 22 & 40 \\
\hline Baseball Speed (mph) & 40 & 70 & 80 & 90 & & $\mathrm{n} / \mathrm{a}$ \\
\hline Depth (mm) & 6.5 & 13.6 & 17.0 & 21.6 & & $\mathrm{n} / \mathrm{a}$ \\
\hline
\end{tabular}

See the text below for more details.

a 40-mph baseball. Getting shot with a .45 caliber bullet resembles getting hit with a 90-mph baseball.

Fast baseballs were similar to large caliber bullets (on armor) in denting putty (see Fig. 9) except for the .44 magnum. The .44 magnum dented the putty to a $40-\mathrm{mm}$ depth or about twice the depth of the 90-mph baseballs. The 90-mph baseballs made 21.6-mm-deep dents in putty on average. This is similar to the depths of the dents from a .40 caliber $(19 \mathrm{~mm})$, a .45 caliber $(22 \mathrm{~mm})$, and a .357 magnum $(21 \mathrm{~mm})$ bullets. A .38 caliber bullet made a 15-mm-deep dent in armor-clad putty. This depth is between the mean depth values of the 70-mph $(13.6 \mathrm{~mm})$ and the $80-\mathrm{mph}(17 \mathrm{~mm})$ baseballs. Table $\mathrm{V}$ summarizes these results.

The second way compared the correlation and regression slopes of the two types of impacts. The experiments found that the mean depth of a baseball's impact and the depth of a bullet's armor-impact both correlated with projectile momentum (see Fig. 9). The baseball impacts had correlation $R^{2}=0.93$, regression equation $y=-6.155+5.188 x$, and $p$-value $<0.001$ where $x$ was a baseball's momentum in $\mathrm{kg} \mathrm{m} / \mathrm{s}$ and $y$ was the putty deformation depth in $\mathrm{mm}$. The bullet-armor impacts had similar correlation $R^{2}=0.97$, regression equation $y=-2.12+4.76 x$, and $p$-value $<0.001$.

The putty-impact regression lines had similar slopes $\beta_{1} \approx 5$ for the baseball impacts $\left(\beta_{1}=5.188\right)$ and the bullet-armor impacts $\left(\beta_{1}=4.766\right)$. Fig. 9 suggests that the two lines are parallel: Same slope with different intercepts. But the multipleregression-based Chow test [25], [26] gave only that the two regression lines differed for $F=61.826$, degrees of freedom $(2,62)$, and $p$-value $<0.001$. So we applied a modified Chow test (Gujarati-Chow test [27]) to test whether the slope terms $\beta_{1}$ differed, the intercept terms $\beta_{0}$ differed, or both.

The Gujarati-Chow test was a multiple regression analysis with a dummy variable approach [25], [27] that compared two groups of data. It used a binary dummy variable $D$ (see the Appendix) to test separately whether the slope terms $\beta_{1}$ differed and whether the intercept terms $\beta_{0}$ differed. The slope-term $\left(\beta_{1}\right)$ test statistics were $t=0.855$ and $p$-value $=0.396$. The two putty-impact regression lines had statistically indistinguishable slopes because we retained the null hypothesis that the slope terms were identical at the standard significance levels $\alpha=0.05$ and $\alpha=0.01$. This confirmed that the putty-backed baseball impacts and the bullet-armor impacts had the same slope $\beta_{1}$ in their regression lines as Fig. 9 suggested.

The intercept-term $\left(\beta_{0}\right)$ test statistics were $t=-4.995$ and $p$-value $<0.001$. The putty-impact regression lines had statistically distinct intercepts because we rejected the null hypothesis that the intercept terms were identical at the standard sig- 


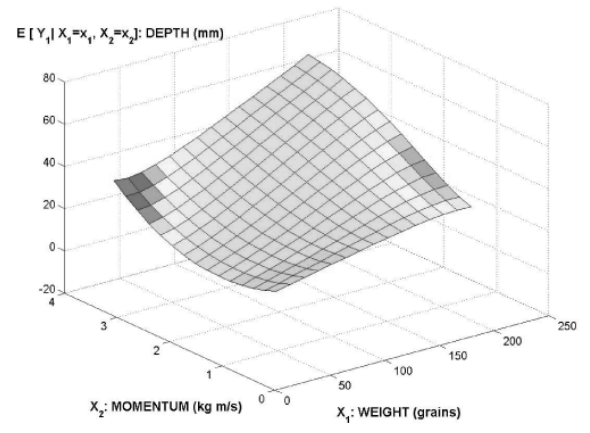

(a) TUNED DEPTH: $E\left[Y_{1} \mid X_{1}=x_{1}, X_{2}=x_{2}\right]$

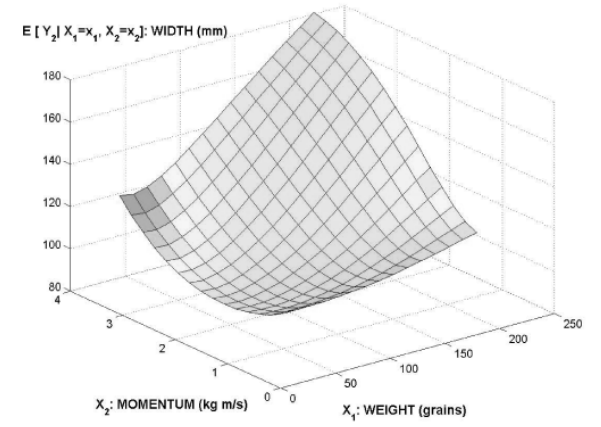

(c) TUNED WIDTH: $E\left[Y_{2} \mid X_{1}=x_{1}, X_{2}=x_{2}\right]$

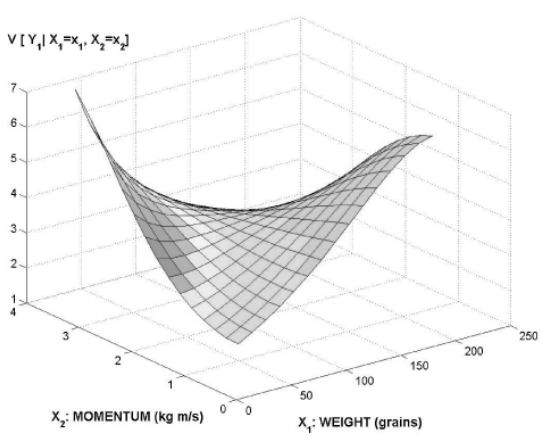

(b) $V\left[Y_{1} \mid X_{1}=x_{1}, X_{2}=x_{2}\right]$

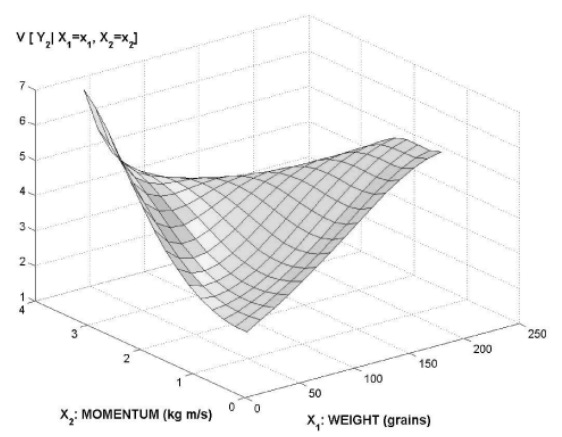

(d) $V\left[Y_{2} \mid X_{1}=x_{1}, X_{2}=x_{2}\right]$

Fig. 10. Tuned fuzzy system output and conditional variance. The complete set of experimental data trained the fuzzy system from the initial states in Fig. 3 .

nificance levels $\alpha=0.05$ and $\alpha=0.01$. This confirmed the Chow-test result that the two regression lines were distinct.

We note that the regulation baseball's constant weight implied that the correlation between deformation and speed was the same as the correlation between deformation and momentum. This corroborated the results from the first gelatin-backed bullet-armor experiments.

\section{FUZZY EXPERT AND GUNSHOT ARMOR BRUISE}

\section{A. Fuzzy System Setup}

The adaptive SAM fuzzy system used the learning laws (7), (9), (10) to learn from the gelatin-backed bullet-armor experimental data. We used the two-dimensional joint factorable sinc function (see Fig. 3) for the if-part fuzzy sets $A_{j}$. Sinc sets often converge faster and with greater accuracy than do triangles, Gaussian bell curves, Cauchy bell curves, and other familiar set shapes [24]. We used scalar Gaussian set functions for the one-dimensional then-part fuzzy sets $B_{j}$. This gave the set variance $\sigma_{B_{j}}^{2}$ from the then-part set volume $V_{j}: \sigma_{B_{j}}^{2}=V_{j}^{2} / 2 \pi$.

A larger then-part rule volume $V_{j}$ produced more uncertainty in the $j$ th rule and so should result in less weight. So we weighted each rule with the inverse of its squared volume [5]: $w_{j}=1 / V_{j}^{2}$. This gave the final form of the SAM output $F$ from (2)

$$
F(x)=\frac{\sum_{j=1}^{m} \frac{a_{j}(x)}{V_{j}} c_{j}}{\sum_{j=1}^{m} \frac{a_{j}(x)}{V_{j}}}=\sum_{j=1}^{m} p_{j}(x) c_{j} .
$$

A larger volume $V_{j}$ also gave a larger conditional variance.
We picked the fuzzy system's initial rules according to the observed correlations in Table I: Same-weight bullets hit harder if they were faster. Same-speed bullets hit harder if they were heavier. But heavier and slower handgun bullets can hit harder than some lighter and faster ones. The adaptive SAM system used 49 rules according to Table II. The if-part set functions $a_{j}$ used center and width parameters to uniformly cover the input space. The then-part set functions $b_{j}$ used center parameters or centroids $c_{j}$ that gave an output according to Tables II(a) and (b) and used volume or dispersion parameters in (c) that reflected the uncertainty of the rules. The fuzzy sets in Table II listed the initial rules that we created based on our experience with ballistics and soft body armor. The volume $V_{j}$ was a function of the then-part's dispersion or width parameter. A rule was less certain if its if-part covered untested combinations of bullet weight and momentum so its then-part had a larger set variance. Fig. 4 shows the fuzzy system's initial first-order output $F(x)=E[Y \mid X=x]$ and second-order uncertainty $V[Y \mid X=x]$.

A random resampling scheme selected half of the sparse experimental data as the bootstrapped training set and the remaining half as the test set. A bootstrap scheme [28] sampled the training data with replacement at random to generate 300 sets of input-output data to tune the fuzzy system.

\section{B. Fuzzy System Results}

We used two sets of the experimental data to train the fuzzy system: Dataset (1) was complete and Dataset (2) excluded the .357-magnum data. Tuning with Dataset (1) reduced the fuzzy system's error function SSE $=\sum_{x}(f(x)-F(x))^{2}$ that summed the squared approximation error $f-F$ for 3000 epochs of learning. Fig. 10 shows the tuned system 


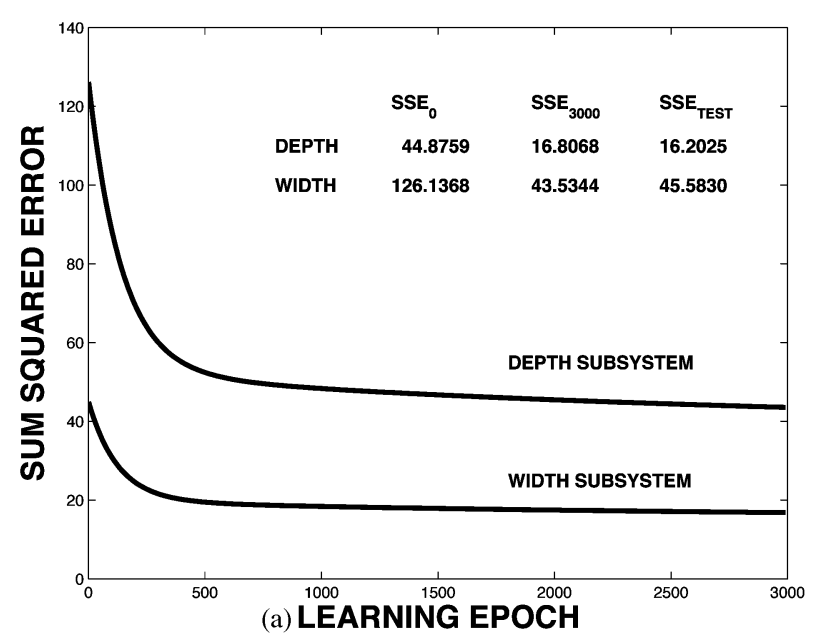

Complete Dataset

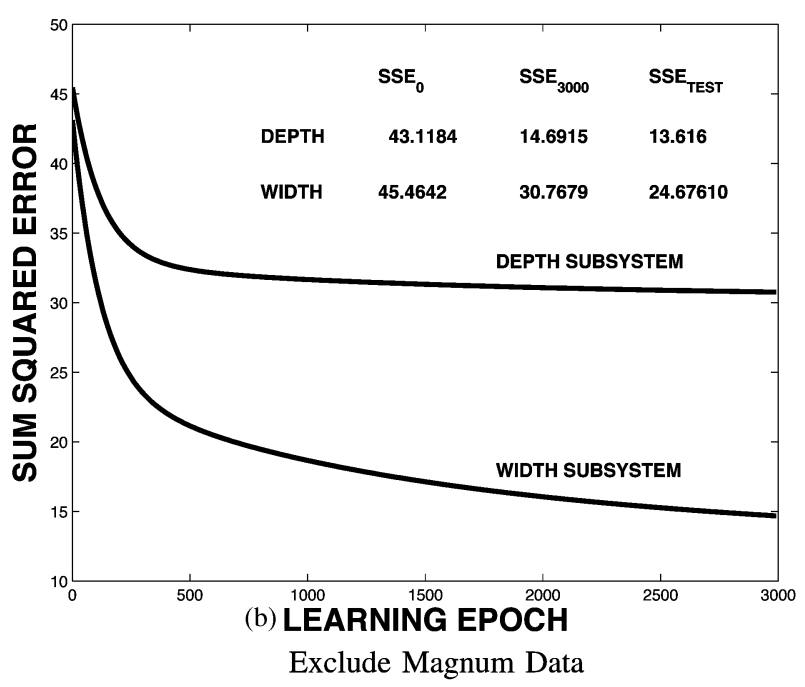

Fig. 11. Learning curve. Tuning reduced the fuzzy system's sum squared error (SSE) of the function approximation for two subsets of data: Dataset (1) was complete and Dataset (2) excluded the .357 magnum data. The depth subsystem in (a) reduced its SSE from 45 to 17 over 3000 epochs of learning and had test $\mathrm{SSE}=16$. The width subsystem in (a) reduced its SSE from 126 to 44 and had test SSE $=46$. The depth subsystem in (b) reduced its SSE from 43 to 15 and had test SSE $=14$. The width subsystem in (b) reduced its SSE from 45 to 31 and had test SSE $=25$.

output $F(x)=E[Y \mid X=x]$ and its conditional variance $V[Y \mid X=x]$. The tuning was effective because the depth subsystem had an initial error of SSE $=45$, final error of SSE $=17$, and low test error of SSE $=16$ and because the width subsystem had initial SSE $=126$, final SSE $=44$, and low test SSE $=46$ [see Fig. 11(a)].

Tuning with Dataset (2) produced system output $F(x)$ and conditional variance $V[Y \mid X=x]$ similar to the initial state in Fig. 4. The fuzzy system's final SSE resembled its initial SSE after tuning even though the low test SSE suggested that the tuning was effective: The depth subsystem had an initial error of $\mathrm{SSE}=43$, final error of SSE $=15$, and test error of SSE $=14$ and the width subsystem had initial SSE $=45$, final SSE $=31$, and test SSE $=25$ [see Fig. 11(b)]

We tested the robustness of the tuned fuzzy system by randomly pruning its rules (see Fig. 12). The fuzzy system proved robust both when the learning included the magnum data and when it did not. Pruning randomly removed a fraction of the rules over 100 trials. The depth and the width subsystems gave similar results. The maximal test error remained low (SSE < 100) for random rule loss of up to $20 \%$ using Dataset (1) and up to $10 \%$ using Dataset (2). The low test SSE was comparable to the approximation errors in data tuning. Both the mean and the median of the test error remained low for random pruning that removed up to $30 \%$ of the rules using Dataset (1) and 20\% using Dataset (2).

\section{CONCLUSION}

The adaptive SAM system modeled the bruise profile of a bullet impact based on bullet-armor experiments. The fuzzy system's output conditional variance measured the inherent uncertainty in the rules. A baseball analogy gave further insight into armor gunshots based on baseball-impact experiments. The bullet-armor experiments found correlations between a bullet impact's depth and width and the bullet's weight and momentum. These correlations were stronger than the correlation between a bullet's impact and its kinetic energy. The baseball correlations corroborated the bullet-armor results.

The findings from the bruise analysis should help engineers design lighter and thinner armor that reduces a bullet's bruising effect while improving the armor user's mobility. These results would benefit from further testing with more than one weight per caliber and with higher speed projectiles. Measurements of the deformed armor would also be more accurate if they came from highspeed photographs of the bullet-armor experiments rather than from the post-impact deformation. The post-impact measurements tended to give smaller values because the elastic gelatin blocks often reduced the armor deformation by springing back after bullet impact.

The bruising effect of flexible armor will change as armor technology evolves. New armor designs can reduce bulletarmor deformation. One such example is the use of colloidal shear-thickening fluid in fluid-impregnated Kevlar fabric. The shear-thickening fluid enhances the penetration resistance of flexible armor [30]. The United States Army is developing armor that uses nanomaterials and nanodevices [31] such as molecular chain mail that uses a mixture of nanoscopic materials [32]. These new materials change how armor deforms on bullet impact and so will change the bruising effect. Test data from the new armor designs can tune the fuzzy rules and so adapt the fuzzy function approximator.

\section{APPENDIX A \\ SAM THEOREM}

This Appendix derives the basic ratio structure (2) of an SAM fuzzy system [5], [24].

SAM Theorem: Suppose the fuzzy system $F: R^{n} \rightarrow R^{p}$ is a standard additive model: $F(x)=\operatorname{Centroid}(B(x))=$ Centroid $\left(\sum_{j=1}^{m} w_{j} a_{j}(x) B_{j}\right)$ for if-part joint set function $a_{j}: R^{n} \rightarrow[0,1]$, rule weights $w_{j} \geq 0$, and then-part fuzzy set 


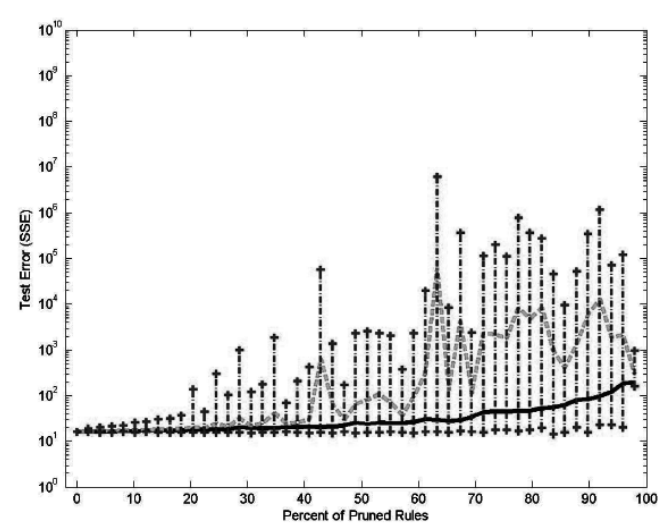

(a) DEPTH RULE PRUNING

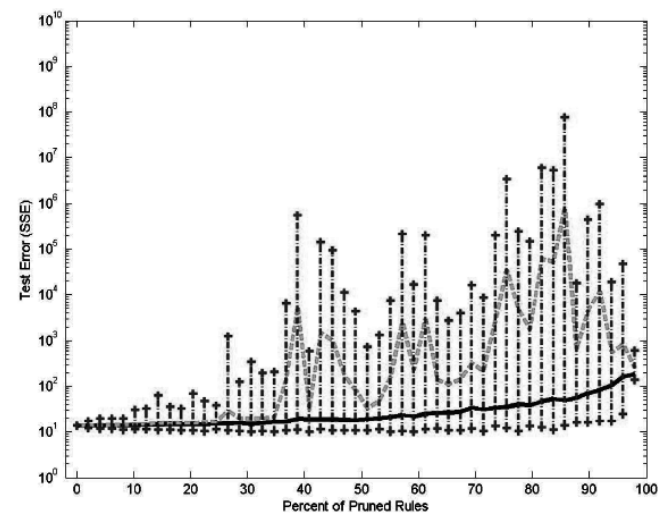

(c) DEPTH EXCLUDE MAGNUM

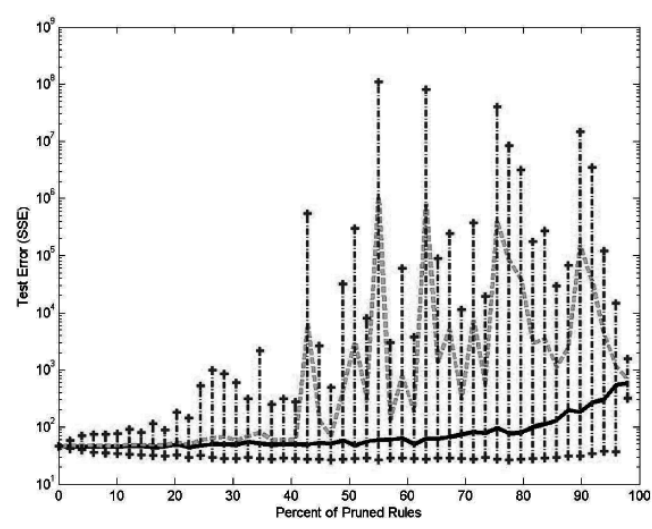

(b) WIDTH RULE PRUNING

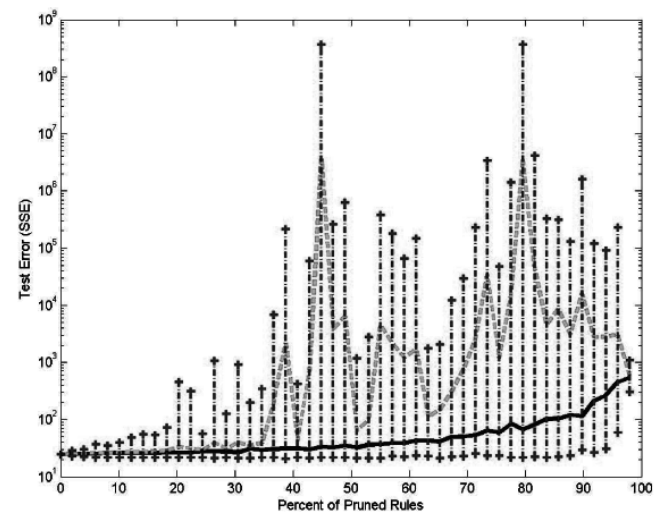

(d) WIDTH EXCLUDE MAGNUM

Fig. 12. Rule pruning. The fuzzy system was robust against random pruning. The figure plots the system's test error in log scale versus the percent of pruned depth rules in (a). Similar results hold for random pruning of width rules in (b) and for pruning rules that trained without magnum data in (c) and (d). The vertical bars show the maximal and minimal range of 100 trials. The solid polygonal line interpolates the median of those trials. The dashed line interpolates the mean. The maximal error remained below 100 SSE for up to $20 \%$ of randomly pruned rules. Both the mean and median error remained low for rule losses of up to $35 \%$.

$B_{j} \subset R^{p}$. Then $F(x)$ is a convex sum of the $m$ then-part set centroids

$$
F(x)=\frac{\sum_{j=1}^{m} w_{j} a_{j}(x) V_{j} c_{j}}{\sum_{j=1}^{m} w_{j} a_{j}(x) V_{j}}=\sum_{j=1}^{m} p_{j}(x) c_{j} .
$$

The convex coefficients or discrete probability weights $p_{1}(x), \ldots, p_{m}(x)$ depend on the input $x$ through

$$
p_{j}(x)=\frac{w_{j} a_{j}(x) V_{j}}{\sum_{i=1}^{m} w_{i} a_{i}(x) V_{i}}
$$

where $V_{j}$ is the finite positive volume (or area if $p=1$ ) and $c_{j}$ is the centroid of then-part set $B_{j}$

$$
\begin{aligned}
V_{j} & =\int_{R^{p}} b_{j}\left(y_{1}, \ldots, y_{p}\right) d y_{1} \ldots d y_{p}>0 \\
c_{j} & =\frac{\int_{R^{p}} b_{j}\left(y_{1}, \ldots, y_{p}\right) d y_{1} \ldots d y_{p}}{\int_{R^{p}} b_{j}\left(y_{1}, \ldots, y_{p}\right) d y_{1} \ldots d y_{p}} .
\end{aligned}
$$

\section{APPENDIX B}

\section{AdDitive STATISTICS THEOREM [5]}

Suppose $F: R^{n} \rightarrow R$ is an additive fuzzy system with scalar output such that $F(x)=\operatorname{Centroid}(B(x))$ and $B(x)=\sum_{j=1}^{m} w_{j} B_{j}^{\prime}(x)$. Then

$$
\begin{aligned}
F(x) & =E[Y \mid X=x] \\
& =\sum_{j=1}^{m} p_{j}(x) E_{B_{j}^{\prime}}[Y \mid X=x] \\
V[Y \mid X=x] & =\sum_{j=1}^{m} p_{j}(x) V\left[Y \mid X=x, B_{j}^{\prime}\right]
\end{aligned}
$$

the convex coefficients $p_{j}(x)$ are weighted volume ratios of the "fired" sets $B_{j}^{\prime}$

$$
p_{j}(x)=\frac{w_{j} V_{j}^{\prime}(x)}{\sum_{k=1}^{m} w_{k} V_{k}^{\prime}(x)}
$$

where

$$
V_{j}^{\prime}(x)=\int b_{j}^{\prime}(x, y) d y
$$

Proof: The proof that centroidal fuzzy systems are conditional means follows from the ratio structure of the centroid and the boundedness and non-negativity of the set values $b(x, y) \geq$ 
0 of the combined set $B$ of "fired" then-part sets $B_{j}$. Each input $x$ gives its own $B(x)$ and thus its own output $F(x)$

$$
\begin{aligned}
F(x) & =\text { Centroid }(B(x)) \\
& =\frac{\int_{R^{p}} y b(x, y) d y}{\int_{R^{p}} b(x, y) d y} \\
& =\int_{R^{p}} y p(y \mid x) d y \\
& =E[Y \mid X=x]
\end{aligned}
$$

for each $x \in R^{n}$. This holds because the ratio of the joint distribution to the marginal defines a proper conditional probability density

$$
p(y \mid x)=\frac{b(x, y)}{\int_{R^{p}} b(x, y) d y}
$$

even though $b(x, y)>1$ may hold.

Then we continue the same chain of equalities to show that $F(x)$ is a convex sum of local conditional mean realizations or centroids

$$
\begin{aligned}
F(x) & =\frac{\sum_{j=1}^{m} w_{j} \int_{-\infty}^{\infty} y b_{j}^{\prime}(x, y) d y}{\sum_{j=1}^{m} w_{j} \int_{-\infty}^{\infty} y b_{j}^{\prime}(x, y) d y} \\
& =\frac{\sum_{j=1}^{m} w_{j} V_{j}^{\prime} \int_{-\infty}^{\infty} y b_{j}^{\prime}(y \mid x) d y}{\sum_{j=1}^{m} w_{j} V_{j}^{\prime}} \\
& =\sum_{j=1}^{m} p_{j}(x) E_{B_{j}^{\prime}}[Y \mid X=x] \\
& =\sum_{j=1}^{m} p_{j}(x) c_{j}^{\prime} .
\end{aligned}
$$

The variance (covariance) result follows in the same way:

$$
\begin{aligned}
V[Y \mid X=x]= & \frac{\int_{-\infty}^{\infty}(y-E[Y \mid X=x])^{2} b(x, y) d y}{\int_{-\infty}^{\infty} b(x, y) d y} \\
= & \sum_{j=1}^{m} p_{j}(x) \int_{-\infty}^{\infty}(y-E[Y \mid X=x])^{2} \\
& \times p_{B_{j}^{\prime}}(y \mid x) d y \\
= & \sum_{j=1}^{m} p_{j}(x) V\left[Y \mid X=x, B_{j}^{\prime}\right] .
\end{aligned}
$$

The SAM structure $B_{j}^{\prime}(x)=a_{j}(x) B_{j}$ simplifies the conditional variance $V_{B_{i}^{\prime}}[Y \mid X=x]$ because the conditional probability density $p_{B_{j}^{\prime}}(y \mid x)$ does not depend on the input $x$ for $a_{j}(x)>0$

$$
\begin{aligned}
p_{B_{j}^{\prime}}(y \mid x) & =\frac{a_{j}(x) b_{j}(y)}{a_{j}(x) \int_{R^{p}} b_{j}(y) d y} \\
& =\frac{b_{j}(y)}{\int_{R^{p}} b_{j}(y) d y}=\frac{b_{j}(y)}{V_{j}}=p_{B_{j}}(y) .
\end{aligned}
$$

Then we use these facts to simplify the first-order and secondorder conditional statistics of an SAM system. It gives the SAM conditional variance as a convex sum of the local then-part variances plus a global dispersion term.

Corollary (SAM Statistics): The scalar-valued SAM system

$$
F(x)=\text { Centroid }\left(\sum_{j=1}^{m} w_{j} a_{j}(x) B_{j}\right)
$$

has conditional mean and variance

$$
E[Y \mid X=x]=F(x)=\sum_{j=1}^{m} p_{j}(x) c_{j}
$$

and

$$
V[Y \mid X=x]=\sum_{j=1}^{m} p_{j}(x) \sigma_{B_{j}}^{2}+\sum_{j=1}^{m} p_{j}(x)\left(c_{j}-F(x)\right)^{2}
$$

with convex coefficients

$$
p_{j}(x)=\frac{w_{j} a_{j}(x) V_{j}}{\sum_{k=1}^{m} w_{j} a_{j}(x) V_{j}} .
$$

The second term in (38) acts as a penalty term. It is positive if and only if some $j$ th rule fires $\left(a_{j}(x)>0\right.$ and thus $\left.p_{j}(x)>0\right)$ and $c_{j} \neq F(x)$. So it is positive iff the fuzzy system $F$ interpolates to reach the output $F(x)$. Each rule comes with its own output uncertainty $\sigma_{B_{i}}^{2}$. Interpolated outputs have more variance than just the sum of these weighted rule variances. Combining two uncertain structures gives a still less certain third structure.

\section{APPENDIX C \\ LEARNING LAWS FOR SCALAR AND JOINT FACTORABLE IF-PART SETS}

This Appendix derives the learning laws for scalar and joint factorable if-part sets [24]. Supervised gradient descent can tune all the parameters in the SAM (2). A gradient descent learning law for a SAM parameter $\xi$ has the form

$$
\xi(t+1)=\xi(t)-\mu_{t} \frac{\partial E}{\partial \xi}
$$

where $\mu_{t}$ is a learning rate at iteration $t$. We seek to minimize the squared error $E(x)=(1 / 2)(f(x)-F(x))^{2}$ of the function approximation. The vector function $f: R^{n} \rightarrow R^{p}$ has components $f(x)=\left(f_{1}(x), \ldots, f_{p}(x)\right)^{T}$ and so does the vector function $F(x)$. We consider the case when $p=1$. A general form for multiple output when $p>1$ expands the error function $E(x)=\|f(x)-F(x)\|$ for some norm $\|\cdot\|$. Let $\xi_{j}^{k}$ denote the $k$ th parameter in the set function $a_{j}$. Then the chain rule gives the gradient of the error function with respect to the if-part set parameter $\xi_{j}^{k}$ with respect to the then-part set centroid $c_{j}=\left(c_{j}^{1}, \ldots, c_{j}^{p}\right)^{T}$ and with respect to the then-part set volume $V_{j}$

$$
\frac{\partial E}{\partial \xi_{k}^{j}}=\frac{\partial E}{\partial F} \frac{\partial F}{\partial a_{j}} \frac{\partial a_{j}}{\partial \xi_{k}^{j}}, \quad \frac{\partial E}{\partial c_{j}}=\frac{\partial E}{\partial F} \frac{\partial F}{\partial c_{j}},
$$


and

$$
\frac{\partial E}{\partial V_{j}}=\frac{\partial E}{\partial F} \frac{\partial F}{\partial V_{j}}
$$

where

and

$$
\frac{\partial E}{\partial F}=-[f(x)-F(x)]=-\varepsilon(x)
$$

$$
\frac{\partial F}{\partial a_{j}}=\left(c_{j}-F(x)\right) \frac{p_{j}(x)}{a_{j}(x)}
$$

The SAM ratios (2) with inverse-squared-volume rule weights $w_{j}=1 / V_{j}^{2}$ give

$$
\begin{aligned}
& \frac{\partial F}{\partial c_{j}}=\frac{\frac{a_{j}(x)}{V_{j}}}{\sum_{j=1}^{m} \frac{a_{j}(x)}{V_{j}}}=p_{j}(x) \\
& \frac{\partial F}{\partial V_{j}}=-\frac{p_{j}(x)}{V_{j}}\left(c_{j}-F(x)\right) .
\end{aligned}
$$

Then the learning laws for the then-part set centroids $c_{j}$ and volumes $V_{j}$ have the final form

$$
\begin{aligned}
c_{j}(t+1) & =c_{j}(t)+\mu_{t} \varepsilon_{t}(x) p_{j}(x) \\
V_{j}(t+1) & =V_{j}(t)-\mu_{t} \varepsilon_{t}(x) \frac{p_{j}(x)}{V_{j}}\left[c_{j}-F(x)\right] .
\end{aligned}
$$

The learning laws for the if-part set parameters follow in like manner for both scalar and joint sets as we show below. Chain rule gives for scalar sinc set function

$$
\frac{\partial E}{\partial m_{j}^{k}}=\frac{\partial E}{\partial F} \frac{\partial F}{\partial a_{j}} \frac{\partial a_{j}}{\partial m_{j}^{k}} \text { and } \frac{\partial E}{\partial d_{j}^{k}}=\frac{\partial E}{\partial F} \frac{\partial F}{\partial a_{j}} \frac{\partial a_{j}}{\partial d_{j}^{k}} .
$$

A joint factorable set function $a_{j}(x)=a_{j}^{1}(x) \ldots a_{j}^{n}(x)$ leads to a new form for the error gradient. The gradient with respect to the parameter of the $j$ th set function $a_{j}$ has the form

where

$$
\frac{\partial E}{\partial m_{j}^{k}}=\frac{\partial E}{\partial F} \frac{\partial F}{\partial a_{j}} \frac{\partial a_{j}}{\partial a_{j}^{k}} \frac{\partial a_{j}^{k}}{\partial m_{j}^{k}}
$$

$$
\frac{\partial a_{j}}{\partial a_{j}^{k}}=\prod_{i \neq k}^{n} a_{j}^{i}\left(x_{i}\right)=\frac{a_{j}(x)}{a_{j}^{k}\left(x_{k}\right)} .
$$

The partial derivative of the joint factorable sinc set function is

$$
\frac{\partial a_{j}^{k}}{\partial m_{j}^{k}}=\left(a_{j}^{k}(x)-\cos \left(\frac{x_{k}-m_{j}^{k}(t)}{d_{j}^{k}(t)}\right)\right) \frac{1}{x-m_{j}^{k}(t)}
$$

where $a_{j}(x)=\prod_{1}^{k} \operatorname{sinc}\left(\frac{x_{k}-m_{j}^{k}}{d_{j}^{k}}\right)$

$$
\text { and } \operatorname{sinc}(x)=\frac{\sin (x)}{x} \text {. }
$$

Combining (40), (41), and (47)-(49) gives the if-part learning laws

$$
\begin{aligned}
m_{j}^{k}(t+1)= & m_{j}^{k}(t)+\mu_{t} \varepsilon_{t} \frac{p_{j}(x)}{a_{j}(x)} \frac{a_{j}(x)}{a_{j}^{k}\left(x_{k}\right)}\left(c_{j}-F(x)\right) \\
& \times\left(a_{j}(x)-\cos \left(\frac{x-m_{j}^{k}(t)}{d_{j}(t)}\right)\right) \frac{1}{x-m_{j}^{k}(t)}
\end{aligned}
$$

$$
\begin{aligned}
d_{j}^{k}(t+1)= & d_{j}^{k}(t)+\mu_{t} \varepsilon_{t} \frac{p_{j}(x)}{a_{j}(x)} \frac{a_{j}(x)}{a_{j}^{k}\left(x_{k}\right)}\left(c_{j}-F(x)\right) \\
& \times\left(a_{j}(x)-\cos \left(\frac{x-m_{j}^{k}(t)}{d_{j}(t)}\right)\right) \frac{1}{d_{j}^{k}(t)} .
\end{aligned}
$$

\section{APPENDIX D \\ HYPOTHESIS TEST FOR $\beta_{1}=c$ FOR SIMPLE LINEAR REGRESSION}

This section reviews the hypothesis test whether the slope term of a simple linear regression equation has a certain value $c: \mathbf{H}_{0}: \beta_{1}=c$ versus $\mathbf{H}_{a}: \beta_{1} \neq c$ [29]. The simple linear regression model for $n$ observations has the form

$$
y=\beta_{0}+\beta_{1} x+\epsilon
$$

where the independent variable $x$, dependent variable $y$, and error term $\epsilon$ are $n \times 1$ vector representations of the $n$ observations. The prediction equation

$$
y=\hat{\beta}_{0}+\hat{\beta}_{1} x
$$

uses the least squares estimators

$$
\hat{\beta}_{1}=\frac{\sum_{i=1}^{n}\left(x_{i}-\bar{x}\right)\left(y_{i}-\bar{y}\right)}{\sum_{i=1}^{n}\left(x_{i}-\bar{x}\right)^{2}} \text { and } \hat{\beta}_{0}=\bar{y}-\hat{\beta}_{1} \bar{x} .
$$

The test statistic is

$$
t=\frac{\hat{\beta}_{1}-c}{\sqrt{\sum_{i=1}^{n}\left(x_{i}-\bar{x}\right)^{2}}}
$$

$$
\text { where } s^{2}=\frac{\text { SSE }}{n-2} \text { and SSE }=\sum_{i=1}^{n}\left(y_{i}-\hat{y}_{i}\right)^{2} .
$$

The test rejects the null hypothesis $\mathbf{H}_{0}$ if the test statistic $|t| \geq$ $t_{\alpha / 2, n-2}$. We note that $t$ has a noncentral distribution $t(n-2, \delta)$ with noncentrality parameter $\delta$ that has the form

$$
\delta=\frac{E\left(\hat{\beta}_{1}\right)}{\sqrt{\operatorname{var}\left(\hat{\beta}_{1}\right)}}=\frac{\beta_{1}}{\sum_{i=1}^{n}\left(x_{i}-\bar{x}\right)^{2}} .
$$

The hypothesis test for $\mathbf{H}_{0}: \beta_{1}=0$ versus $\mathbf{H}_{a}: \beta_{1} \neq 0$ can use (55)-(56) for $c=0$ and $\delta=0$. 


\section{APPENDIX E \\ MultiPle REGRESSION ANALYSIS AND THE DUMMY VARIABLE APPROACH (GUJARATI-CHOW TEST)}

Multiple regression [25] can compare two groups with an unequal numbers of samples. The dummy variable approach [27] can compare the two groups' linear regression coefficients to see whether they have different intercepts, different slopes, or both. This modifies the Chow test [26] that tests whether both the intercepts and slopes differ between the two groups.

The Gujarati-Chow test is a multiple regression analysis that uses a dummy variable $D[25]$, [27] to create interaction terms. The test concatenates the data from the two groups and uses the binary dummy variable $D$ to determine whether a data sample belongs to Group A or Group B as shown in the equation at the bottom of the page. The dummy-variable regression equation has the form

$$
y=a_{0}+a_{1} D+a_{2} x+a_{3}(D x)
$$

where $x$ is the independent variable and $y$ is the dependent variable for both groups of data. The dummy variable $D$ is in both an additive and a multiplicative form. The constants $a_{1}$ and $a_{3}$ are the differential intercept and differential slope coefficients. The Gujarati-Chow test performs a multiple linear regression and can test two null hypothesis: $\mathbf{H}_{0}^{a_{1}}: a_{1}=0$ and $\mathbf{H}_{0}^{a_{3}}: a_{3}=0$.

The intercept value of Group A's data is $a_{1}+a_{0}$ if $a_{1}$ is statistically significant then $a_{0}$ is the intercept value of Group B's data in this case. Else $a_{0}$ estimates the intercept term of both groups of data if $a_{1}$ is statistically insignificant (large $p$-value).

The slope of Group A's data is $a_{3}+a_{2}$ if $a_{3}$ is statistically significant then $a_{2}$ is the slope of Group B's data in this case. Else $a_{2}$ estimates the slope term of both groups of data if $a_{3}$ is statistically insignificant (large $p$-value). The additive and multiplicative dummies give whether two linear regressions differ either in the intercept or the slope or both.

We want to test the null hypothesis $\mathbf{H}_{0}$ that the two regression slopes are identical for the bullet-armor impact data (Group A) and the baseball impact data (Group B). This tests the hypothesis $\mathbf{H}_{0}: a_{3}=0$ versus $\mathbf{H}_{a}: a_{3} \neq 0$. The hypothesis test retains the null hypothesis for a high $p$-value: $a_{3}$ is not statistically significant and $a_{2}$ estimates the slope term of both the bullet-armor data and the baseball data.

\section{REFERENCES}

[1] Second Chance Saves. Central Lakes, MI: Second Chance, 1999, pp. $7-16$.

[2] A. Jason and M. L. Fackler, "Body armor standards: A review and analysis," IWBA Wound Ballistics Rev., vol. 1, no. 1, pp. 14-37, 1992.

[3] "Ballistic Resistance of Personal Body Armor and Stab Resistance of Personal Body Armor," National Institute of Justice (NIJ) Standards, NIJ Standard-0101.04, 2004

[4] R. A. Santucci and Y.-J. Chang, "Ballistics for physicians: Myths about wound ballistics and gunshot injuries," J. Urol., vol. 171, pp. 1408-1414, Apr. 2004.
[5] B. Kosko, Fuzzy Engineering. Englewood Cliffs, NJ: Prentice-Hall, 1996.

[6] D. W. Walsh and J. Hagen, "Body armor: What it is and what it does," J. Emerg. Med. Serv., pp. 66-67, Sep. 1994.

[7] D. MacPherson, "Dynamic projectile interactions and associated body armor effects," IWBA Wound Ballistics Rev., vol. 1, no. 4, pp. 29-31, 1994.

[8] M. C. Andrews and R. J. Young, "Fragmentation of aramid fibers in single-fiber model composites," J. Mat. Sci., vol. 30, no. 22, pp. 5607-5616, Nov. 1995.

[9] D. MacPherson, L. Ed Fincel Miloskovich, and J. Nicholas, "Body armor penetration dynamics," IWBA Wound Ballistics Rev., vol. 3, no. 2, pp. 16-24, 1997.

[10] P. M. Cunniff, "A semiempirical model for the ballistic impact performance of textile-based personnel armor," Textile Res. J., vol. 66, no. 1, pp. 45-59, Jan. 1996.

[11] I. S. Chocronbenloulo, J. Rodriguez, and A. Sanchezgalvez, "A simple analytical model to simulate textile fabric ballistic impact behavior," Textile Res. J., vol. 67, no. 7, pp. 520-528, Jul. 1997.

[12] R. L. Ellis, F. Lalande, H. Y. Jia, and C. A. Rogers, "Ballistic impact resistance of SMA and spectra hybrid graphite composites," J. Reinforced Plastics Composites, vol. 17, no. 2, pp. 147-164, 1998.

[13] T. E. Bachner Jr, "The V-50 ballistic limit: A reliable test for body armor," IWBA Wound Ballistics Rev., vol. 1, no. 4, pp. 20-25, 1996.

[14] D. MacPherson, Bullet Penetration: Modeling the Dynamics and the Incapacitation Resulting From Wound Trauma. El Segundo, CA: Ballistic, 1994.

[15] _ "The dynamics of tissue simulation," IWBA Wound Ballistics Rev., vol. 3, no. 1, pp. 21-23, 1997.

[16] M. L. Fackler and J. A. Malinowski, "The wound profile: A visual method for quantifying gunshot wound components," J. Trauma, vol. 25 , no. 6 , pp. $522-529,1985$.

[17] A. J. Ryan MD, "Traumatic injuries: Office treatment of deep bruises," Postgrad. Med., vol. 59, no. 6, pp. 195-197, 1976.

[18] G. A. Galanti, Caring for Patients From Different Cultures, 2nd ed. Philadelphia, PA: Univ. of Pennsylvania Press, 1997.

[19] T. Stephenson and Y. Bialas, "Estimation of the age of bruising," Arch Disease Childhood, vol. 74, no. 1, pp. 53-55, Jan. 1996.

[20] V. B. Pai and M. W. Kelly, "Bruising associated with the use of fluoxetine," Ann. Pharmacotherapy, vol. 30, no. 7-8, pp. 786-788, 1996.

[21] A. W. Carroll and C. A. Soderstrom, "A new nonpenetrating ballistic injury," Ann. Surgery, vol. 188, no. 6, pp. 753-757, Dec. 1978.

[22] G. C. Velmahos, R. Tatevossian, and D. Demetriades, "The seat belt mark sign: A call for increased vigilance among physicians treating victims of motor vehicle accidents," Amer. Surgeon, vol. 65, no. 2, pp. $181-185,1999$.

[23] A. Hunt, G. Dorshimer, J. Kissick, and S. Ryan, "Isolated jejunal rupture after blunt trauma," Physician Sportsmed., vol. 9, no. 11, Nov. 2001.

[24] S. Mitaim and B. Kosko, "The shape of fuzzy sets in adaptive function approximation," IEEE Trans. Fuzzy Syst., vol. 9, no. 4, pp. 637-656, Aug. 2001.

[25] R. Ramanathan, Introductory Econometrics with Applications, 4th ed Fort Worth, TX: Dryden, 1998.

[26] G. Chow, "Tests of equality between sets of coefficients in two linear regressions," Econometrica, vol. 28, no. 3, pp. 591-605, 1960.

[27] D. Gujarati, "Use of dummy variables in testing for equality between sets of coefficients in two linear regressions: A note," Amer. Statistician, vol. 24 , no. 1 , pp. 50-52, 1970.

[28] A. M. Zoubir and B. Boashash, "The bootstrap and its application in signal processing," IEEE Signal Process. Mag., vol. 15, no. 1, pp. 56-76, Jan. 1998.

[29] A. C. Rencher, Linear Models in Statistics. New York: Wiley, 2000.

[30] Y. S. Lee, E. D. Wetzel, and N. J. Wagner, "The ballistic impact characteristics of kevlar woven fabrics impregnated with a colloidal shear thickening fluid," J. Mat. Sci., vol. 38, pp. 2825-2833, 2003.

[31] (2002) Army Selects MIT for $\$ 50$ Million Institute to Use Nanomaterials to Clothe, Equip Soldiers. MIT News Office. [Online]. Available: http://web.mit.edu/newsoffice/nr/2002/isn.html

[32] (2003) ISN Projects Include Armor Made of Nanoscopic Material MIT News Office. [Online]. Available: http://web.mit.edu/newsoffice/tt/2003/sep24/isn.html 


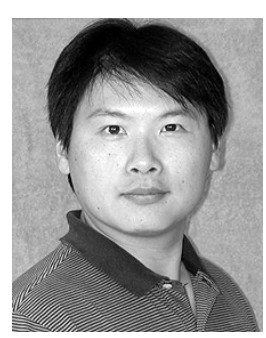

Ian Lee received the B.S. and M.S. degrees in electrical engineering from the University of Michigan, Ann Arbor, in 1992 and 1994, respectively. He received the Ph.D. degree in electrical engineering at the University of Southern California, Los Angeles, in 2005 .

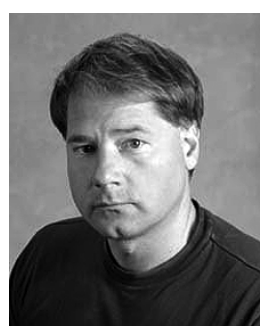

Bart Kosko (M'85) received B.A. degrees in philosophy and economics from the University of Southern California, Los Angeles, the M.A. degree in applied mathematics from the University of California at San Diego, and the Ph.D. degree in electrical engineering from the University of California at Irvine.

$\mathrm{He}$ is a Professor of electrical engineering with the University of Southern California, Los Angeles. He is the author of the textbooks Neural Networks and Fuzzy Systems (Englewood Cliffs, NJ: Prentice-Hall, 1992) and Fuzzy Engineering (Englewood Cliffs, NJ: Prentice-Hall, 1997), the novel Nanctime (New York: Avon, 1997), the trade books Fuzzy Thinking (New York: Hyperion, 1993) and Heaven in a Chip (New York: Random House, 2000). He edited Neural Networks for Signal Processing (Englewood Cliffs, NJ: Prentice-Hall, 1992) and coedited (with Simon Haykin) Intelligent Signal Processing (New York: IEEE/Wiley, 2001).

Dr. Kosko is an Elected Governor of the International Neural Network Society and has chaired and cochaired many neural and fuzzy system conferences.

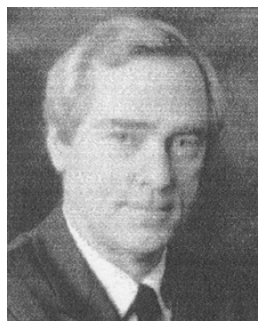

W. French Anderson was born and raised in Tulsa, OK, and received the A.B. degree (magna cum laude) in biochemical sciences from Harvard College, Cambridge, MA, in 1958, the M.A. degree (honors) in natural sciences from Trinity College, Cambridge University, Cambridge, U.K., in 1960, and the M.D. degree (magna cum laude) from Harvard Medical School in 1963.

$\mathrm{He}$ is the Director of the Gene Therapy Laboratories at the Keck School of Medicine, University of Southern California (USC), Los Angeles, where he also serves as a Professor of biochemistry and pediatrics, is a Full Member of the Norris Comprehensive Cancer Center, and is the Program Coordinator for Gene Therapy in the Institute of Genetic Medicine. Before joining the USC faculty in 1992, he was Chief of the Molecular Hematology Branch at the National Heart, Lung, and Blood Institute at the National Institutes of Health (NIH), where he worked as a Gene Therapy Researcher for 27 years and was also Chairman of the Department of Medicine and Physiology in the NIH Graduate Program.

Dr. Anderson headed the team that carried out the first approved human gene therapy clinical protocol in 1990, is recognized as an ongoing innovator in the research area of human gene transfer, and is also known as a leading ethicist in the field of human genetic engineering. He has been called the "Father of Gene Therapy." 